Document downloaded from:

http://hdl.handle.net/10251/82708

This paper must be cited as:

Payri, R.; Gimeno, J.; Bracho Leon, G.; Vaquerizo, D. (2016). Study of liquid and vapor phase behavior on Diesel sprays for heavy duty engine nozzles. Applied Thermal Engineering. 107:365-378. doi:10.1016/j.applthermaleng.2016.06.159.

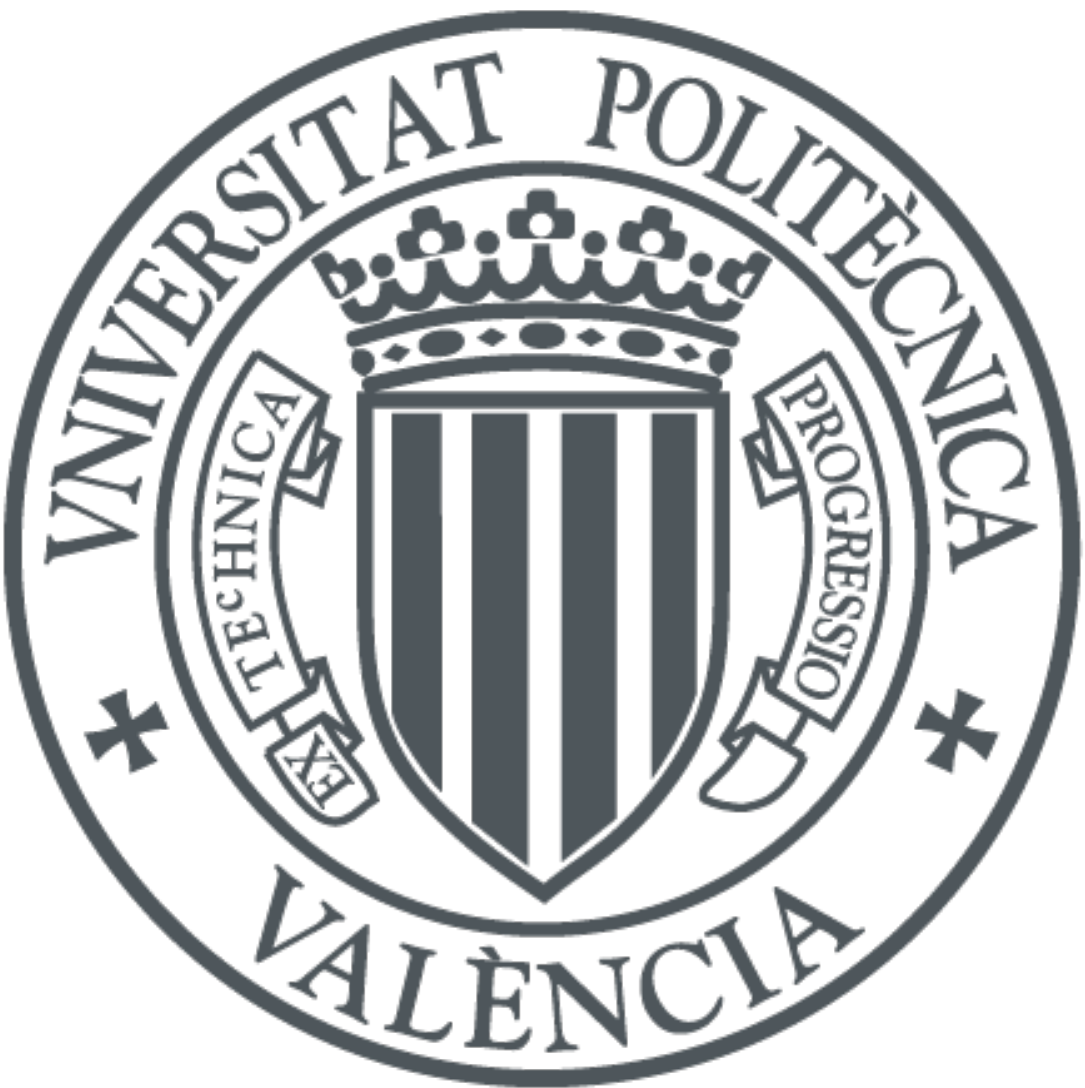

The final publication is available at

http://doi.org/10.1016/j.applthermaleng.2016.06.159

Copyright Elsevier

Additional Information 


\title{
Study of liquid and vapor phase behavior on Diesel sprays for heavy duty engine nozzles
}

\author{
R.Payri, J.Gimeno, G.Bracho*, D.Vaquerizo \\ CMT-Motores Térmicos. Universitat Politècnica de València. Camino de Vera s/n, E-46022 Valencia, \\ Spain.
}

\begin{abstract}
A lot of effort has been put in the past years into the understanding of the delivery and development of diesel sprays in engine-like conditions as it has been proved to be a very important step for the design of better and cleaner commercial engines. Due to the bigger share of passenger cars engines over heavy duty engines, the research has been mainly focused on the investigation using small nozzles. This paper studies two nozzles with diameters representative of those that can be encountered in heavy duty engines, with the objective of corroborating the conclusions gathered for small nozzles representative of passenger car engines. The experimental data have been acquired by state-of-the-art techniques and equipment, and serves two purposes: further the understanding of the physics involved in the injection event and spray evaporation; and provide a dataset to CFD models that can accurately predict the behavior of the injection event.

The tests were performed in a constant pressure flow vessel that allows to simulate enginelike conditions (1000 K and $15 \mathrm{Mpa}$ ) with continuous flow. The injection system tested is a novel, common-rail, solenoid-actuated injector for heavy duty applications which operates up to $220 \mathrm{Mpa}$. All experiments were performed in non-reacting conditions. The extended test matrix allowed to determine the influence of several parameters such as rail pressure, gas temperature, gas density, and nozzle geometry on the air-fuel mixing and evaporation process, by analyzing the spray penetration and spreading angle. Mie scattering and double-pass Schlieren optical configurations have been used to measure global liquid and vapor penetration, respectively.

The data proves that spray penetration at low temperature can be up to $15 \%$ faster than spray penetration at high temperature conditions at the same density for the nozzles experimented, which limits the usability of low temperature experiments to infer the behavior of the injector at high temperature conditions. The data also shows that the nozzle with the biggest diameter provided the highest value of stabilized liquid length as expected. Also, when vapor phase is reached, the temperature has negligible effect on the global diesel spray morphology, and no influence on the tip penetration or on the spreading angle.
\end{abstract}

Keywords: Heavy duty engines, Diesel spray, Schlieren, Mie scattering, Vapor, Liquid, Penetration 
Final author version, cite as:

R. Payri, J. Gimeno, G. Bracho, D. Vaquerizo, Study of liquid and vapor phase behavior on Diesel sprays for heavy duty engine nozzles. Applied Thermal Engineering 107 (2016) 365-378. doi:10.1016/j.applthermaleng.2016.06.159

\section{Nomenclature}

Table 1: Nomenclature used in the document.

\begin{tabular}{rr}
\hline $\mathrm{S}$ & Penetration \\
D194 & $194 \mu \mathrm{m}$ nozzle \\
D228 & $228 \mu \mathrm{m}$ nozzle \\
HPHT & High Pressure High Temperature \\
PID & Proportional Integrative Derivative \\
CMOS & Complementary Metal-Oxide Seminconductor \\
ASoI & After Start of Injection \\
ASoE & After Start of Energizing \\
ID & Ignition Delay \\
LOL & Lift Off Length \\
LL & Liquid Length \\
CPFR & Xenon arc \\
Xe-arc & Constant Pressure Flow Rig \\
$\Delta \mathrm{P}$ & Drop between inlet and outlet \\
$\rho_{a}$ & Density of the ambient gas \\
$\rho_{f}$ & Density of the fuel \\
$C_{a}$ & Area coefficient \\
$C_{v}$ & Velocity coefficient \\
$T_{\text {gas }}$ & Tressure Derature of the ambient gas \\
$D_{0}$ & Outlet diameter of nozzle \\
$\theta$ & Spray plume cone angle \\
$t_{r}$ & Transition time \\
\hline
\end{tabular}

\section{Introduction}

Energy consumption and emissions production from internal combustion engines remains the two most important key factors in the design and development of engines $[1,2]$. The harmful effect of the exhaust gases to the ambient and public health resulting from the combustion, combined with the limited amount of available energy, create the need to limit, as heavily as possible, the level of pollution and $\mathrm{CO}_{2}$ that engines are allowed to produce [3]. The increasingly demanding emission regulations creates a tough challenge to researchers working in the engines industry to provide advanced combustion solutions that can comply with the normative. The effort dedicated to research on the field of diesel engines has been, and still is, very large.

In the particular case of off-road heavy duty diesel engines, the emission regulations have been less stringent than those of the light duty engines, therefore the efforts for

\footnotetext{
*Corresponding author

Email address: gbracho@mot.upv.es (G.Bracho)
} 
Final author version, cite as:

R. Payri, J. Gimeno, G. Bracho, D. Vaquerizo, Study of liquid and vapor phase behavior on Diesel sprays for heavy duty engine nozzles. Applied Thermal Engineering 107 (2016) 365-378. doi:10.1016/j.applthermaleng.2016.06.159

improvements and the amount of research for this application is not as numerous $[4,5]$. Nevertheless, the recent legislation for heavy duty applications on behalf of reducing fuel consumption and pollutant emissions have pushed the industry to develop new technologies and combustion strategies that address those concerns and challenges.

Most of the recent topics of research in the engine community are being performed mainly for downsized engine type specifications with very small nozzle diameters (80$100 \mu \mathrm{m}$ ), in order to understand how the nozzle geometry influences the diesel injection process and spray development. One example is the Engine Combustion Network $[6,7,8]$. Those studies also involve the development of numerical models, either based on physical assumptions or simply interpolating experimental data. However, regarding bigger nozzle diameters the up-to-date information available is limited. Most of the documentation available focused on diesel injection processes for nozzles with relatively big diameters was written one or two decades ago, when the injector technology reached lower injection pressure levels, the actuating systems had a different performance, and the experimental equipment were not as good as the optical and electronic devices that are used nowadays. For instance, Naber and Siebers [9] in 1996, studied the ambient gas density and fuel vaporization effects on diesel spray penetration and dispersion using big size nozzles of about $198-340 \mu \mathrm{m}$, reaching injection pressure levels of about 150MPa. Later in 1999, Siebers [10] studied the effects that the most important parameters have in the liquid phase penetration and cone angle and developed a theoretical scaling law that was adjusted by means of intensive experimental campaigns. Siebers [10] found a linear dependence of liquid length on orifice diameter, a relevant and non-linear inverse effect of the gas temperature on liquid length and an insignificant effect of injection pressure. The test matrix performed by Siebers [10] included an extensive range of nozzle diameters from 100 to $498 \mu \mathrm{m}$, densities and temperatures. Undoubtedly, they found significant results; however, the maximum pressure drop in the orifice was about $170 \mathrm{MPa}$ and only the liquid phase was studied.

Considering the aforementioned facts, this research is carried out in order to develop a better understanding of the effect of big nozzle diameters on the atomization and evaporative performance of the spray using up-to-date injection system technology and optical devices, measuring the liquid phase and vapor phase penetration of the fuel spray in engine like conditions. Therefore, in this paper, two different diesel nozzles conceived for medium/heavy duty engine operation have been investigated at different ambient temperatures and gas densities similar to those that the injected spray would encounter in the combustion chamber.

The paper starts describing the experimental set-up and methodologies; first by presenting the nozzles and injection systems, along with the High Pressure and High Temperature constant pressure test rig, and followed by the description of the different optical techniques and image processing methodology employed. In the next section, the main results obtained are presented and discussed, the results from this section are then used to create empirical correlations that can describe the behavior of the different variables investigated. To finalize, the last section underlies the main conclusions gathered throughout the work. 
Final author version, cite as:

R. Payri, J. Gimeno, G. Bracho, D. Vaquerizo, Study of liquid and vapor phase behavior on Diesel sprays for heavy duty engine nozzles. Applied Thermal Engineering 107 (2016) 365-378. doi:10.1016/j.applthermaleng.2016.06.159

\section{Methodology}

\subsection{Nozzles and Injection System}

Two similar nozzles with convergent holes have been experimented in this study, which are representative of nozzles for medium/heavy duty engines. Table 2 shows the basic characteristics of the nozzles. Both nozzles have the same orifice length size of $920 \mu \mathrm{m}$ and different outlet diameter. Given the $L / D$ ratio (nozzle length divided by the outlet diameter) the likelihood of cavitating operation is increasing from the D194 to the D228 nozzle [11]. The nozzles are coupled to a common rail type fuel injector with a solenoid type actuation, typical for heavy duty application engines.

Table 2: Nozzles used in the study

\begin{tabular}{lrr}
\hline Nozzle & Diameter $[\mu m]$ & $\mathrm{L} / \mathrm{D}$ \\
\hline D194 & 194.4 & 4.73 \\
D228 & 228.8 & 4.02 \\
\hline
\end{tabular}

The injection system comprises a low pressure pump, a high pressure pump, a common rail regulated with a PID controller and all the necessary high pressure lines and filters for accurate operation. The high pressure pump consists on an electrically driven pump able to reach more than $220 \mathrm{MPa}$ injection pressure and is fed via the low pressure pump. The PID controller actuates opening or closing the common rail in order to achieve the injection pressure desired. Injection pressure is measured with a Kistler pressure sensor directly connected on the common rail. A refrigeration circuit is also employed to avoid overheating of the fuel and the high pressure pump of the injection system.

\subsection{The high pressure high temperature test rig}

The different experimental techniques described in the next sections have been performed in a high pressure high temperature test vessel where the in-cylinder thermodynamic conditions relevant to a diesel engine at the time of injection can be reproduced. The rig belongs in the category of CPFR (Constant Pressure Flow Rig), and allows to maintain stationary conditions at $1000 \mathrm{~K}$ maximum temperature and $15 \mathrm{Mpa}$ maximum pressure. The vessel is equipped with three large windows (128 $\mathrm{mm}$ in diameter) placed orthogonally in order to have complete optical access to the injection event. The complete test rig functioning and principle are precisely described by Payri et al. [12].

Several facilities in the world have the capability of operating at similar conditions $[13,14] ; ?]$ show the boundary conditions of some of the vessels used in the institutions contributing to the Engine Combustion Network (ECN). However, the test rig described here is capable of obtaining nearly quiescent and steady thermodynamic conditions for very long periods of time. This design grants a better, easier control and reproduction of real engine-like test conditions [12].

On the other hand, engines with optical accesses are commonly used for similar purposes $[13,15,16]$. Although they replicate more realistic conditions, they also introduce 
Final author version, cite as:

R. Payri, J. Gimeno, G. Bracho, D. Vaquerizo, Study of liquid and vapor phase behavior on Diesel sprays for heavy duty engine nozzles. Applied Thermal Engineering 107 (2016) 365-378. doi:10.1016/j.applthermaleng.2016.06.159

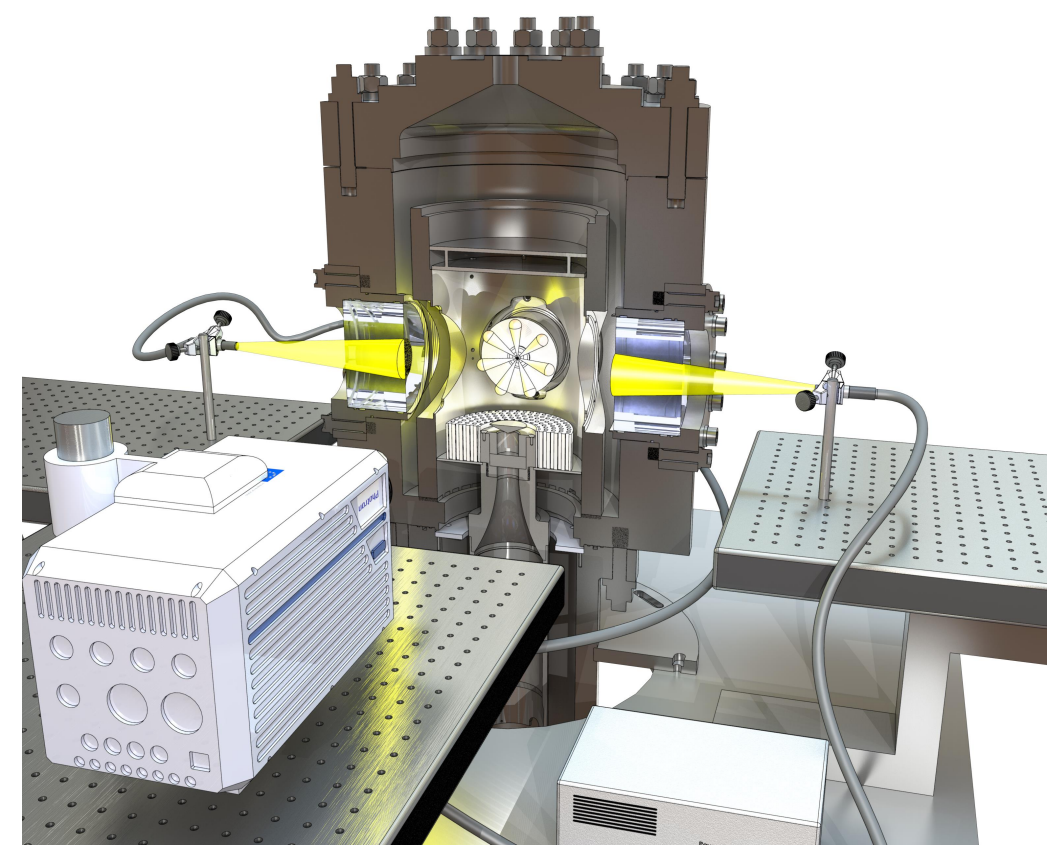

Figure 1: Representation of the set-up for Mie scattering

more uncertainties and variables that can hide fundamental effects otherwise evidently outlined when operating in a controlled environment. Those optical accessible engines, are subject to swirl and turbulent in-cylinder flow, and visualization is greatly restricted by the inherent geometric constrains of an operating engine.

In the test rig used for this study, the steadier thermodynamic conditions provide a high test repetition rate and quality, improving the global accuracy of data acquired and assuring a better discrimination of the variables involved in the processes taking place inside the rig. Furthermore, to isolate the spray behavior physics from the chemical combustion process, non-reacting conditions have been set throughout the tests.

\subsection{Mie scattering}

The Mie scattering imaging technique is widely used in spray research for the liquid phase imaging. The technique consists in illuminating the fuel droplets with a light source and capturing the scattered light with a high speed camera. Many examples of the use and calibration of this technique can be found in the literature [17, 18]. The complete description of the scattering phenomenon is described in [19].

In the tests performed for this study, the spray was illuminated by the lateral windows with two continuous Xe-arc lamps, and the backwards-scattered light collected by a CMOS high speed camera (Photron SA5) aligned with the injector axis. In Fig 1, a representation of the set-up used for the Mie scattering test is shown.

\subsection{Schlieren Imaging}

The optical set-up used to capture the spray macroscopic parameters (vapor penetration), is a double pass Schlieren system [20]. The optical technique consists on directing 
Final author version, cite as:

R. Payri, J. Gimeno, G. Bracho, D. Vaquerizo, Study of liquid and vapor phase behavior on Diesel sprays for heavy duty engine nozzles. Applied Thermal Engineering 107 (2016) 365-378. doi:10.1016/j.applthermaleng.2016.06.159

a collimated beam of light through the test zone (i.e injection spray), and gathering the beam again in the camera sensor filtering or discarding some of the deflected light, to finally form a shadowgraph in which different pixel intensities represent different refractive indexes in the region of interest [21]. Being a multi-hole nozzle injector, frontal visualization was necessary to capture all the spray plumes. This imposes the use of a two pass (or double pass) system with a mirror downstream of the injector nozzle, where the technical challenge was to operate at very high temperatures and preserve the integrity of the mirror. A representation of the optical set-up used is shown in fig. 2. The yellow and orange translucent beams represent the paths of the light before and after reaching the mirror, respectively. The beam splitter separates the light on the way to the mirror and the light on the way back from it. Both the single point light source, and the Fourier filtering diaphragm are purposely located at the focal length of Lens B.

The collimated beam of light resulting from Lens B is subject to deviations from the original parallel path due to differences in density between the ambient air, and liquid and/or vapor phases of the spray. The light deviated (twice) from the original path (the deviation can be small or large depending on whether it was produced by the liquid or vapor phase), is prevented from entering the high speed camera sensor by means of the aforementioned Fourier filtering diaphragm. The device used consists of an adjustable diameter diaphragm which lets light past its center hole while blocking the rest. This would fall in the category of a circular type cut-off device, which performs symmetrically if everything is properly aligned. The diameter of the center hole is adjustable so that it is possible to decide how much light is to be allowed into the camera. This adjustment is what actually controls the system's sensibility, by letting the user decide how much deflected light gets into the camera sensor.

For quick reference, Table 3 show the main configuration parameters of the cameras for the two visualization techniques used.

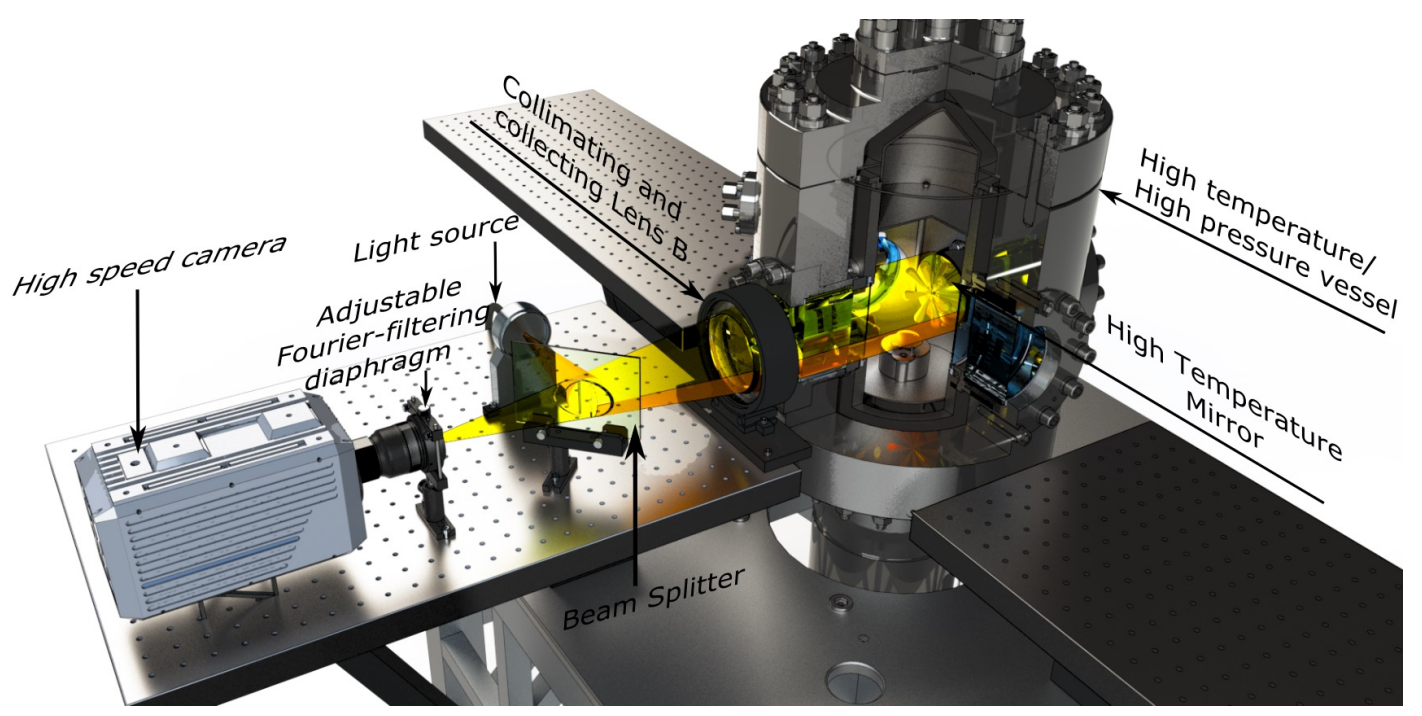

Figure 2: Representation of the optical set-up used for double pass Schlieren imaging. 
Final author version, cite as:

R. Payri, J. Gimeno, G. Bracho, D. Vaquerizo, Study of liquid and vapor phase behavior on Diesel sprays for heavy duty engine nozzles. Applied Thermal Engineering 107 (2016) 365-378. doi:10.1016/j.applthermaleng.2016.06.159

Table 3: Main parameters of the configuration for the cameras used in the two visualization techniques.

\begin{tabular}{llcc}
\hline Optical technique & Camera & fps & Images size [pix] \\
\hline Mie scattering & Photron SA5 & 15000 & $640 \times 640$ \\
Schlieren & Photron SA-X2 & 22500 & $768 \times 744$ \\
\hline
\end{tabular}

\subsection{Image Processing}

The image processing is one of the most important parts of any visualization data analysis $[22,23]$. The images captured with all optical set-ups were processed with a purpose-developed software. The general principles and the contour detection strategies of the image processing are independent of the technique used to gather the images. However, some particularities have to be taken into account to feed the processing software the same kind of images for all cases. This is done by means of a preprocessing software that prepares the images so all of them are viable to be processed in the same way. The preprocessing strategy can be summarized as:

1. Background and spray luminosity. Depending on the optical set-up, the image can be compound by an illuminated spray and dark background or the opposite. The preprocessing code inverts the image when the spray is dark and the background is illuminated so the type of images being fed to the Image Processing software are always the same. Therefore, the inversion of images is done to the ones obtained by the Schlieren technique and no inversion is done to Mie scattering images.

2. Static or dynamic background. The background has been considered static in the case of the Mie scattering Imaging, given that the change throughout the experiment is negligible. In the case of the Schlieren imaging, the background can change significantly in the time the injection event is being recorded. This is because in this type of visualization, the flow inside the high pressure and high temperature chamber is visible. The dynamic background is created in two steps: 1) the background from the last (time-wise) image is put where the last spray contour is not present and 2) the original background image is put where the spray contour was detected in the previous image.

Having the images prepared by the preprocessing code, each image is then divided into sectors, one for every plume of the spray. Each plume is therefore processed separately by masking the rest of the image. The algorithm is described in detail in [24], a representative example for the Schlieren method is shown in fig. 3. First, the image is inverted in order to have the spray as the high luminosity area and the threshold calculated as a certain percentage of the image's dynamic range $[23,24]$. Then small areas that result from the background noise are erased and the spray contour cleaned by means of filtering and spray connectivity criteria. In the bottom right corner image of Fig 3 the original image is shown together with the overlapped contour detected with the process discussed. 

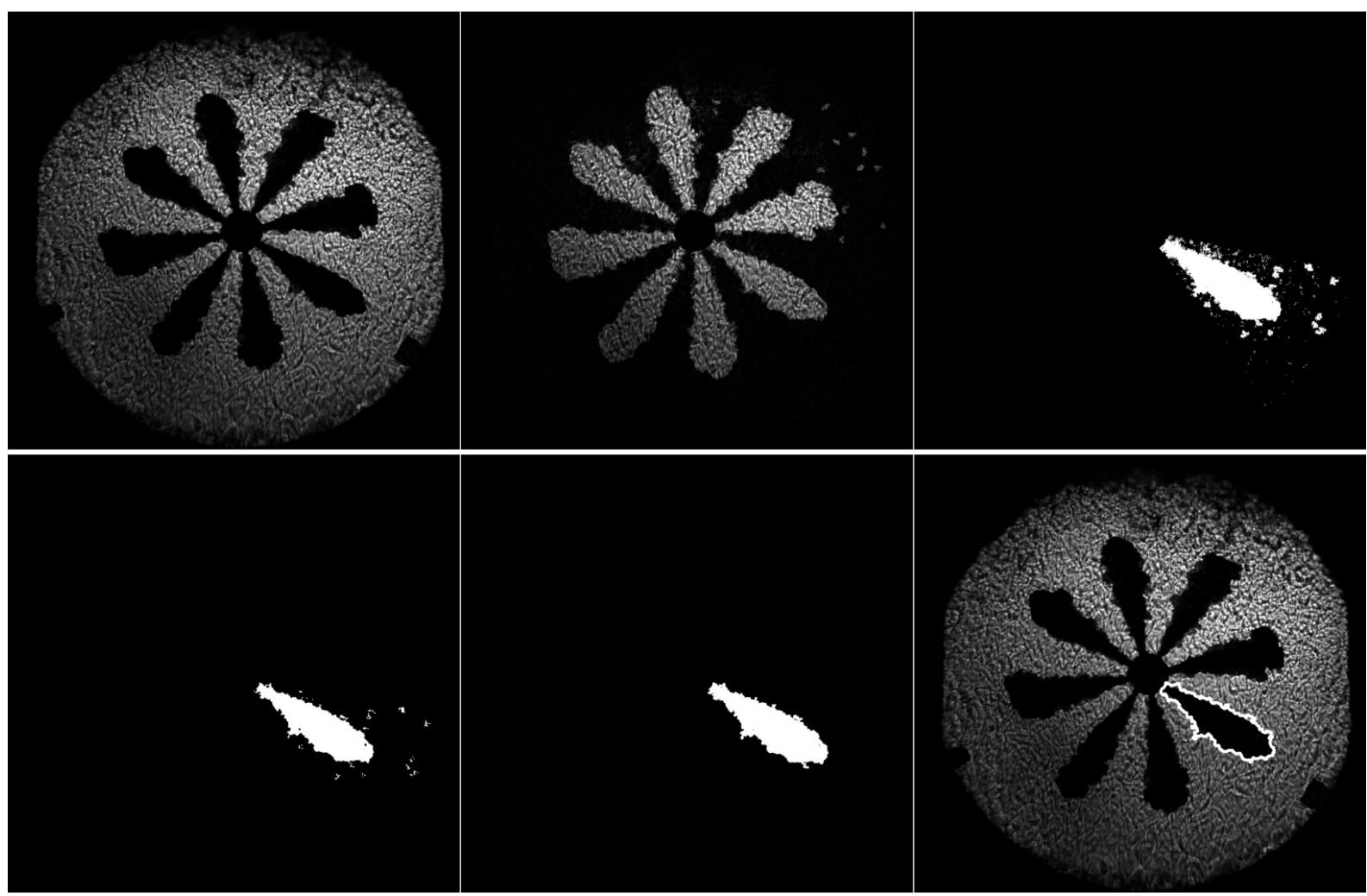

Figure 3: Image sequence example. Top left: original image. Top center: inverted image with substracted background. Top right: image after masking and threshold binarization. Bottom left: image after small area filtering. Bottom center: image after pixel connectivity evaluation. Bottom right: final contour detected and plotted over original image.

The spray spreading angle and the liquid and vapor penetration are obtained by analyzing the contour yielded by the processing algorithm.

\section{Spray penetration}

Liquid penetration (in Mie scattering images) and vapor penetration (in Schlieren images) are calculated by detecting the pixel on the contour that is the furthest from the outlet orifice; the penetration is then calculated as the axial distance from the injector outlet to the furthest point.

\section{Spray spreading angle}

There are several ways of measuring the angle once the contour is detected. The different methods found in the literature can produce substantial differences in the resulting spray spreading angle, therefore it is important to justify the election of one over the others. In this work four definitions have been considered due to their widespread use by the scientific community:

1. Triangle Criteria. The definition is based on the angle of an isosceles triangle. The isosceles triangle is built considering the height as half the spray penetration $(0.5 S)$ and an area equivalent to the spray region from the nozzle exit until the half penetration. This angle definition was described by Naber and Siebers [9]. 
Final author version, cite as:

R. Payri, J. Gimeno, G. Bracho, D. Vaquerizo, Study of liquid and vapor phase behavior on Diesel sprays for heavy duty engine nozzles. Applied Thermal Engineering 107 (2016) 365-378. doi:10.1016/j.applthermaleng.2016.06.159

2. Trapezoid Criteria. This case is similar to the triangle criteria defined by Naber \& Siebers, adapted for cases when the contour of the spray is not available near the nozzle (for instance in double pass Schlieren tests). Here the angle is that of an isosceles trapezoid with the same area than the spray. The base of the trapezoid coincides with the spray contour nearest to the nozzle. The trapezoid method requires that the two lines forming the angle intersect at the geometrical origin of the spray (outlet orifice).

3. Fitted angle between intervals. In this case, two lines are fitted to the contour of the spray, starting at $12 \%$ of the penetration and ending at $60 \%$. The lines might not intersect at the orifice of the nozzle, this means that the origin of the spray is not taken into consideration.

4. Fixed Origin. The origin is fixed and then two lines are fitted using a weighted average of each point in the contour defined in polar coordinates.

Figure 4 graphically defines the points above. Whether in Schlieren Imaging (where the first part of the spray plumes are not available given the non reflective nature of the nozzle tip) or even in Mie scattering (where the lateral illumination may not be enough to reach the first droplets of the spray), it can be noted that the triangle method is very limited. The other three are more robust because they elude the use of the first part of the spray to compute an angle.

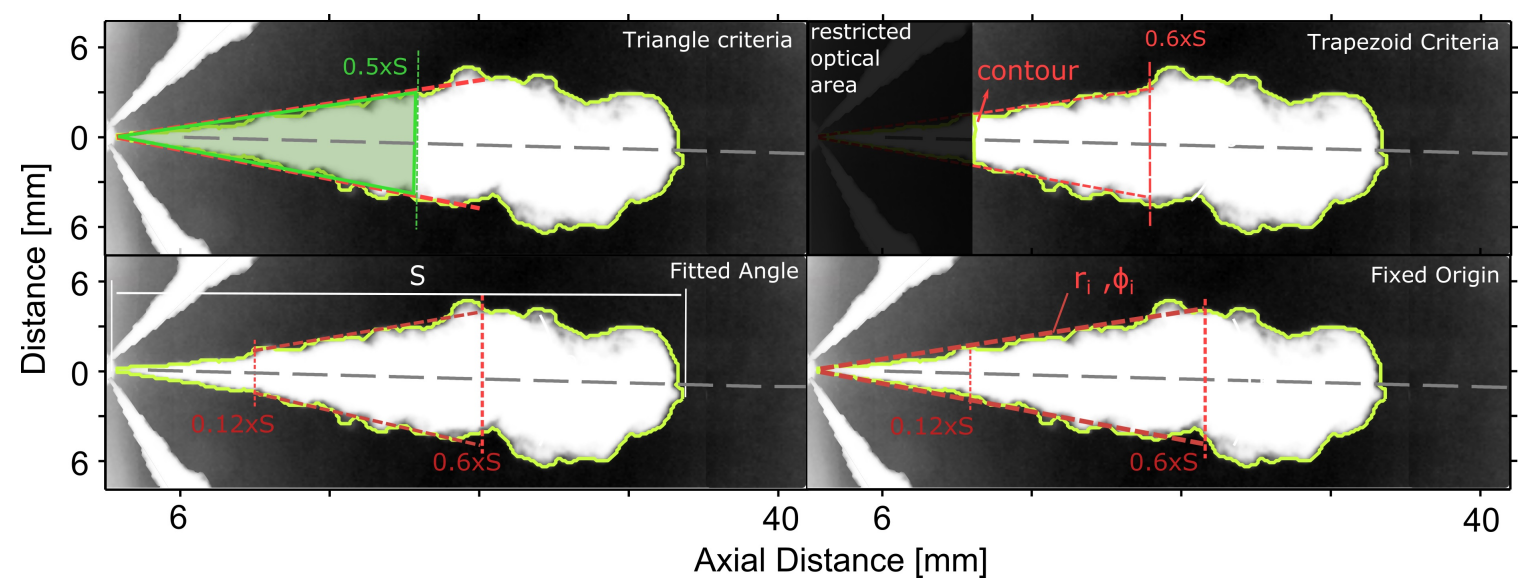

Figure 4: Different spray spreading angle definitions found in the literature.

Figure 5 shows the angle calculated once the processing of the images has been done. The different criteria explained previously have been used to compare their behavior, the triangle method has been left out for its lack of robustness. In this case, Fig. 5a shows the comparison for Mie scattering tests (liquid angle), it can be noted that the first part of the angle does not make much sense, this can be explained recalling the definitions of the angle calculations. When the liquid spray has not yet reached a minimum length, the definitions that make the fitted lines go through the geometrical origin of the spray yield an excessive angle at the beginning, then, the angle drops until a certain length is 
Final author version, cite as:

R. Payri, J. Gimeno, G. Bracho, D. Vaquerizo, Study of liquid and vapor phase behavior on Diesel sprays for heavy duty engine nozzles. Applied Thermal Engineering 107 (2016) 365-378. doi:10.1016/j.applthermaleng.2016.06.159

reached. On the other hand, the definition that does not fix the origin of the spray (fitted angle between lines) behaves more steadily. For Schlieren cases, in Fig 5b the trends are the opposite, this is because in these tests the first part of the contour is not accessible and so, once the vapor is developed enough to be seen, the contour at that point can be broad, and given that in the case of fitted angle method the center can be moved, the algorithm can locate the center very close to the contour, effectively resulting in a very wide angle.

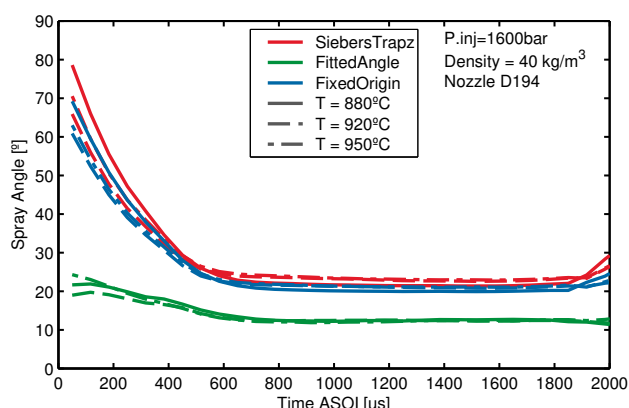

(a) Different criteria for angle computing in Mie scattering tests.

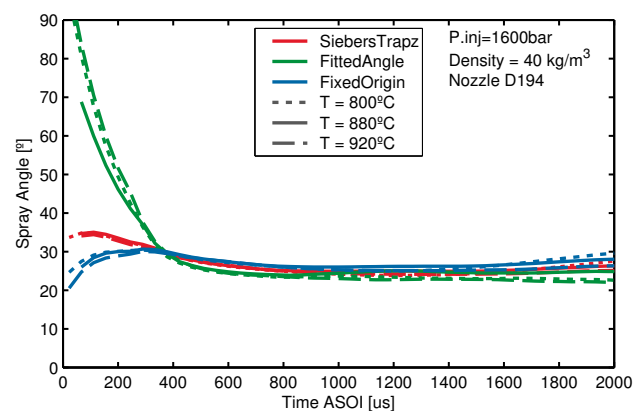

(b) Different criteria for angle computing in Schlieren imaging tests.

Figure 5: Comparison of different criteria used to measure angle

The behavior of the first instants of the angle criteria comparison graphics can be better explained by Fig. 6. This figure shows the spray contours obtained for certain conditions (rail pressure 16MPa and gas temperature 880K) at $1000 \mu \mathrm{s}$ ASOI, the liquid contour can be broad in the first milimiters of the spray which would explain why the angle definitions that force the origin would yield a very big angle when the length of the contour is very small. Moreover, the little slope of the contour would also explain why the calculation following the fitted angle method yields a very small angle, indeed this little slope puts the origin of the calculated center very far away of the geometrical orifice which gives a non valid result. This effect it's not seen on Fig. $5 \mathrm{~b}$ because in this case the slope of the contour is much more pronounced.

\subsection{Data averaging}

A moving average strategy has been implemented in order to obtain the mean value of the parameters measured and to filter the noise inherent to the experimentation. For each experiment, an instantaneous value $y_{i}$ is obtained for the time $t_{i}$ which corresponds to the time elapsed after the start of the injection [12]. The average value $\bar{y}_{i}$ at the instant $t_{i}$ is obtained following this procedure:

- The data set falling in the interval $t_{i} \pm \Delta t / 2$ is considered, with the time window $\Delta t$ set to $9 \mu \mathrm{s}$ for all experiments.

- Over the data set selected, a linear fit is applied and the value of $\bar{y}_{i}$ is obtained substituting $t_{i}$ in the equation resulting from the linear fit. 
Final author version, cite as:

R. Payri, J. Gimeno, G. Bracho, D. Vaquerizo, Study of liquid and vapor phase behavior on Diesel sprays for heavy duty engine nozzles. Applied Thermal Engineering 107 (2016) 365-378. doi:10.1016/j.applthermaleng.2016.06.159

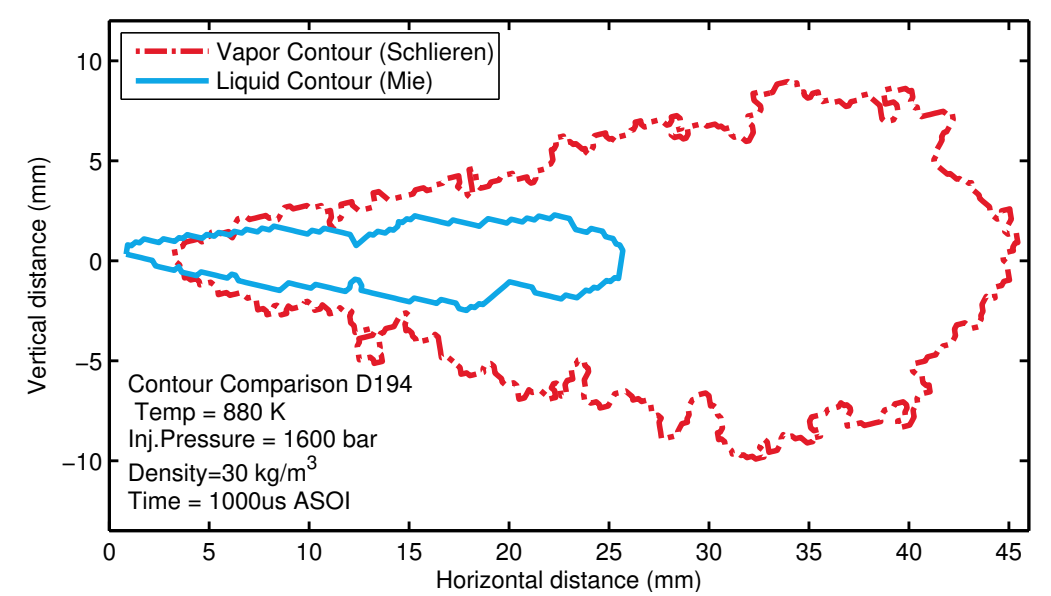

Figure 6: Overlapped contours of vapor and liquid spray for the same temperature, density, pressure, and time conditions.

- This algorithm is repeated by moving $t_{i}$ along the time line with a certain time step selected for each experiment to optimize the averaging of the data.

\subsection{Test Plan}

This section summarizes the conditions tested in the experiments for Mie scattering and Schlieren set-up. The test plan was defined using a design of experiments approach because of the limited time available of the experimental equipment. Table 4 shows the plan followed for the Mie scattering tests, with a total of 25 points; whereas table 5 shows the 17 different conditions collected using Schlieren imaging. The points appearing in bold in Table 5 have been measured using both Mie scattering and Schlieren imaging. The operating conditions shown in the two tables correspond to the D194 nozzle, the D228 Nozzle was measured almost for the same conditions except for the cold spray at $473 \mathrm{~K}$. In all cases the energizing time was $2 \mathrm{~ms}$ in order to ensure long injections with enough period of stabilized mass flow rate.

Table 4: Liquid (Mie scattering) test plan.

\begin{tabular}{llrrr}
\hline Rail Pressure [bar] & Temperature $[\mathrm{K}]$ & Density $\left[\mathrm{kg} / \mathrm{m}^{3}\right]$ & \\
\hline $500-1000-1600-2100$ & 473 & $20-30$ & \\
\cline { 2 - 5 } Nozzle D194 & $500-1000-1600-2100$ & 880 & $20-30-40$ & \\
& 1600 & 880 & 45 & \\
& $500-1600$ & 920 & 40 & Nozzle D228 \\
& $1000-1600-2100$ & 950 & $20-30$ & \\
& $500-1000-1600-2100$ & 950 & 40 & \\
\hline
\end{tabular}

\subsection{0-D spray penetration models}

0 -D or statistical models have been used in section 4 in order to extract the general behavior of the Liquid Length and Vapor Penetration data presented in section 3. The 
Final author version, cite as:

R. Payri, J. Gimeno, G. Bracho, D. Vaquerizo, Study of liquid and vapor phase behavior on Diesel sprays for heavy duty engine nozzles. Applied Thermal Engineering 107 (2016) 365-378. doi:10.1016/j.applthermaleng.2016.06.159

Table 5: Vapor (Schlieren) test plan.

\begin{tabular}{lcc}
\hline Rail Pressure $[\mathrm{bar}]$ & Temperature $[\mathrm{K}]$ & Density $\left[\mathrm{kg} / \mathrm{m}^{3}\right]$ \\
\hline $1000-1600$ & 800 & $30-35-40-45-50$ \\
$1000-1600$ & 880 & $\mathbf{2 0 - 3 0 - 4 0 - 4 5}$ \\
1600 & 920 & $30-\mathbf{4 0}$ \\
\hline
\end{tabular}

objectives are to create a simple tool to validate data extracted in a similar manner when experimenting injectors with similar diameter nozzles, and to compare the models created by other authors in order to find similarities or differences that can contribute in complementing the understanding of the injection processes and spray development in Diesel injectors and to serve as a base of comparison for future research. In the current section, the Liquid Length and Vapor Penetration models are briefly introduced in order to present the general overview before results are presented, leaving the detailed description and discussion in section 4.

\subsubsection{Liquid Length model}

Liquid Length is the maximum length of liquid in a spray that has reached stabilized conditions, where evaporation rate is the same as fuel renovation rate, and therefore, the maximum liquid penetration of the spray remains almost constant. In such conditions, the Liquid Length does not depend on time and as was proved by Siebers [10]. The general theoretical formula that describes the behavior of Liquid Length was proposed by [25] and is presented in (1).

$$
L L=\frac{K_{p}^{2}\left(\frac{1}{4}\right)^{0.5}\left(\frac{\pi}{4}\right)^{0.5} C_{a}^{0.5} \rho_{f}^{0.5} D_{o}}{C_{m v} \rho_{a}^{0.5}}
$$

Where, $\rho_{a}$ and $\rho_{f}$ are the ambient and fuel densities respectively, $C_{a}$ is the area coefficient, $D_{0}$ is the nozzle diameter, $C_{m v}$ is the value of mass concentration in the axis at which the liquid fuel is totally vaporized (a value that depends on the ambient temperature and fuel characteristics) and $K_{p}=k\left(\tan (\theta / 2)^{-0.5}\right.$, where $k$ is a constant and $\theta$ is the spray cone angle.

The specific formula used in this work to fit the experimental data only comprises the variables that were measured and is presented in section 4.2

\subsubsection{Vapor Penetration model}

Contrary to the LL, vapor penetration is dependent on time. The dependence on time varies depending how far the spray has penetrated into the ambient gas, the model used in 4 proposes two regions, as was done by Naber and Siebers [9], Desantes et al. [26]. The first region is close to the nozzle and therefore dominated by the momentum being transfered to the spray in the injection event, in the first region the spray penetration dependence with time is linear $(\mathrm{S} \propto \mathrm{t})$ and the main parameters affecting are pressure difference $(\Delta P)$ and presence of cavitation (proportional to the velocity coefficient $C_{v}$ ). The second region starts when the spray penetration begins to be affected by evaporation and mixing (air entrainment) with the ambient gas, which is proportional to the square 
Final author version, cite as:

R. Payri, J. Gimeno, G. Bracho, D. Vaquerizo, Study of liquid and vapor phase behavior on Diesel sprays for heavy duty engine nozzles. Applied Thermal Engineering 107 (2016) 365-378. doi:10.1016/j.applthermaleng.2016.06.159

root of time $(S \propto \sqrt{t})$. In the second region, the main parameters affecting the vapor penetration are ambient density $\left(\rho_{a}\right)$, orifice area and velocity coefficients $\left(C_{a}\right.$ and $\left.C_{v}\right)$, tangent of the semi-angle of the spray $(\tan \theta / 2)$, nozzle diameter $\left(D_{0}\right)$, and the pressure difference $(\Delta P)$. The theoretical formula proposed by Naber and Siebers [9], and later by Payri et al. [27] has been used as a base to fit the experimental vapor penetration data in section 4.3 and is presented here through equations (2), (3) and (4).

For $t<t_{r}$ :

$$
S(t)=C_{v} \sqrt{\frac{2 \Delta P}{\rho_{f}} t}
$$

For $t>t_{r}$ :

$$
S(t)=\frac{C_{v}^{1 / 2}\left(2 C_{a}\right)^{1 / 4} \Delta P^{1 / 4} D_{0}^{1 / 2} t^{1 / 2}}{\tan (\theta / 2)^{1 / 2} \rho_{a}^{1 / 4}}
$$

Where

$$
t_{r}=\frac{\left(2 C_{a}\right)^{1 / 2}}{C_{v} \tan (\theta / 2)} \frac{\rho_{f} D_{0}}{\left(\rho_{a} \Delta P\right)^{1 / 2}}
$$

\section{Results and discussion}

This section is divided into two different subsections. First, the effect of gas temperature on spray morphology is presented. Here, the spray penetration evolution, the spray spreading angle and spray contours are shown. After that, the effect of nozzle diameter on the liquid length of the spray is presented and compared to the vapor phase of the spray.

For each injection condition, 5 repetitions were performed with an injection frequency of $0.02 \mathrm{~Hz}$ in order to ensure that the diesel-nitrogen mixture is completely evacuated before the subsequent injection event. Every spray is processed separately for each repetition and time step; however, the results presented in this section are the averaged value of measured liquid spray and vapor penetration for all spray plumes and repetitions, in a representative population of the whole data.

\subsection{Effect of gas temperature on spray morphology}

\subsubsection{Nozzle D194}

The effect of the gas temperature on the spray morphology was studied testing different temperatures while maintaining constant the rest of the boundary conditions (gas density and injection pressure), as can be seen in Tables 4 and 5. Since the driving parameter for the spray penetration is the gas density, the chamber pressure was adjusted for each gas temperature in order to keep constant the density. The parametric variation was performed for the two visualization techniques.

Figure 7 shows a comparison of the spray tip penetration at different temperatures for the same density and injection pressure for the D194. This figure comprises the liquid phase penetration obtained via Mie scattering (cross symbol) and the vapor phase penetration measured via Schlieren technique (circle symbol). Regarding the liquid phase, 
Final author version, cite as:

R. Payri, J. Gimeno, G. Bracho, D. Vaquerizo, Study of liquid and vapor phase behavior on Diesel sprays for heavy duty engine nozzles. Applied Thermal Engineering 107 (2016) 365-378. doi:10.1016/j.applthermaleng.2016.06.159

as expected, all curves overlap in the first transient part since ambient density was kept constant. Once the spray tip moves forward, the liquid penetration behaves differently as the gas temperature is higher. At the lowest temperature, the liquid spray penetration advances until the window limit, meanwhile the liquid penetration stops growing at a certain distance when the gas temperature increases, as a consequence of the complete evaporation of the spray. These observations are consistent with other studies $[12,28]$.

Concerning the vapor phase, the figure shows that there is no difference in the vapor spray penetration for the tested temperatures $(800,880$ and $920 \mathrm{~K})$. This fact is also well known in the available literature [12].

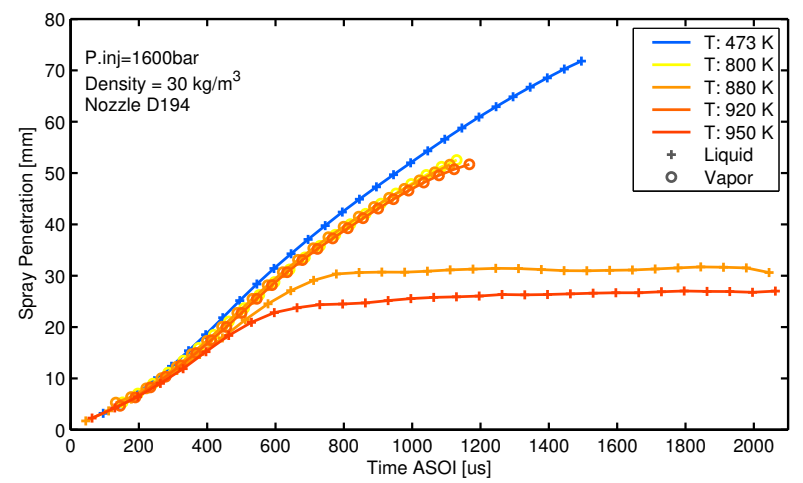

Figure 7: Comparison of the effect of gas temperature on the liquid and vapor spray penetration in D194 Nozzle.

Moreover, this figure compares the vapor phase spray and the liquid spray penetration at the non-vaporizing point $(473 \mathrm{~K})$. From a general overview, both curves have a similar trend, and for this reason other authors have suggested in the past that experiments at low temperature would provide a reasonable estimation of the spray development at engine like conditions (since spray visualization at low temperatures is technically much easier, especially at high density conditions [9]). Although those curves have the same trend, slight differences are visible in the developed region, where the spray penetration at $473 \mathrm{~K}$ is faster. The comparison shows that vaporization decelerates penetration about $15 \%$ as a combination of two facts: the reduction in droplet size due to the evaporation at higher temperature may enhance the momentum transfer from the fuel to the surrounding air [29]; and an increase in the local density of the gas mixture in the spray periphery as it is cooled by evaporating the fuel, which slows the injected fuel progressing through the spray to the tip [9].

The last observation would indicate that there is a difference in the spray angle between a cold spray and a vaporizing one. This fact is shown in Fig 8 where the spray angle at cold conditions is slightly narrower than the vapor angle for the hot sprays, which indicates a lower level of air entrainment and as a consequence of that, the momentum balance might go in favor of a faster penetration. In contrast, it can be noted that temperature has a slight effect on the liquid angle obtained via Mie scattering, this would indicate that temperature also increases the evaporation of fuel in the transversal direction of 
Final author version, cite as:

R. Payri, J. Gimeno, G. Bracho, D. Vaquerizo, Study of liquid and vapor phase behavior on Diesel sprays for heavy duty engine nozzles. Applied Thermal Engineering 107 (2016) 365-378. doi:10.1016/j.applthermaleng.2016.06.159

the sprays, effectively making the liquid phase thinner, which is not surprising given the big influence of temperature on fuel evaporation. However, this conclusion has to be taken cautiously given the higher uncertainty in the determination of angles using Mie scattering. Pickett et al. [18] showed that the determination of Liquid Length using the contour obtained through the scattered light can depend on the direction of the incoming illumination and the maximum intensity value due to the relation to the thresholding algorithm. In this case, spray angle in Mie scattering data is also very sensitive to the uncertainties previously mentioned, as it is dependent on the detected contour from $12 \%$ to $60 \%$ of spray penetration. Fig 9 illustrates this point with three consecutive (time-wise) images from the Mie scattering experiments (left) and from the Schlieren experiments (right) at the same conditions, and approximately the same times (for the liquid-phase and vapor-phase cases the time steps are not exactly the same, since the frame-rate acquisition was different; nevertheless the time steps between the 2 cases were chosen as closely as possible). The images have been cropped to focus only on one of the sprays and the contours detected have been overlapped. It can be seen how despite the smooth surface of the Mie scattering contours in three consecutive images, the general shape of the contour can substantially change; contrary to the Schlieren case in the right side, where the contour is very rough, but the frontier of the spray is much more defined. It is expected that some changes in the shape of the spray in the Mie scattering images are physical due to the turbulent nature of the sprays, but it can also be appreciated how the contrast in the boundary of liquid and background in these images are much less clear than in the right side case, where the big difference between spray and background makes the Schlieren visualization technique more robust and insensitive to the threshold.

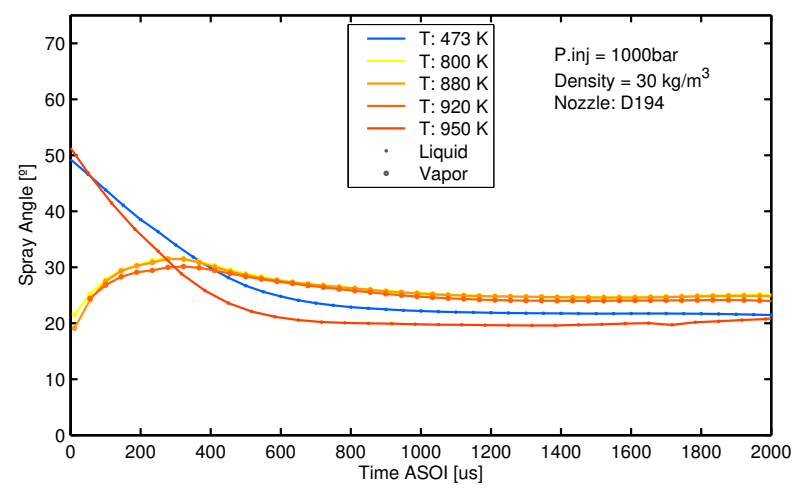

Figure 8: Comparison of the effect of gas temperature for the liquid and vapor spray angles in D194 Nozzle.

Further visualization of the phenomena described in Fig 7 and Fig 8 is shown in Fig 10 where the vaporizing condition at $920 \mathrm{~K}$ and non-vaporizing at $473 \mathrm{~K}$ are shown together. Top and mid part are raw images obtained through the visualization experiments, bottom part depicts the detected contours for the liquid and vapor phases put together (from this point forward, only the detected contours will be shown, as they provide the same information and allow clearer comparisons). It can be noted how the contour for the 
Final author version, cite as:

R. Payri, J. Gimeno, G. Bracho, D. Vaquerizo, Study of liquid and vapor phase behavior on Diesel sprays for heavy duty engine nozzles. Applied Thermal Engineering 107 (2016) 365-378. doi:10.1016/j.applthermaleng.2016.06.159
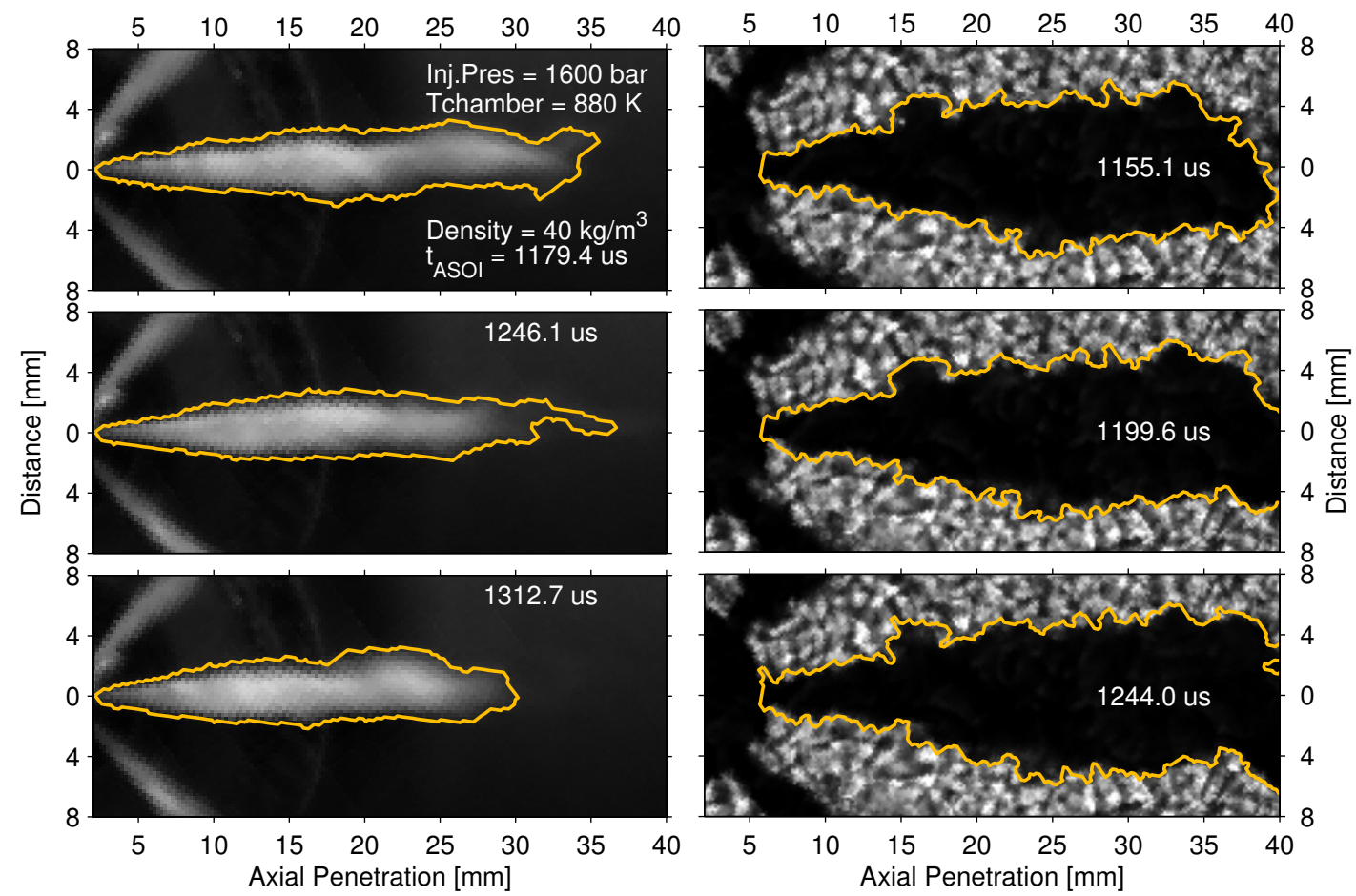

Figure 9: Three consecutive images of Mie scattering (left) and Schlieren (right) at the same conditions and approximately the same times. Images are cropped in order to focus on only one of the sprays. Contour detected via image processing algorithms are plotted over the spray of interest. 
Final author version, cite as:

R. Payri, J. Gimeno, G. Bracho, D. Vaquerizo, Study of liquid and vapor phase behavior on Diesel sprays for heavy duty engine nozzles. Applied Thermal Engineering 107 (2016) 365-378. doi:10.1016/j.applthermaleng.2016.06.159

evaporative spray would yield a slightly wider angle than in the one from the cold spray. Also, in the cold spray, the contour appears much smoother and uniform than in the hot case, which signifies a lower interaction between the injected spray and the ambient gas.

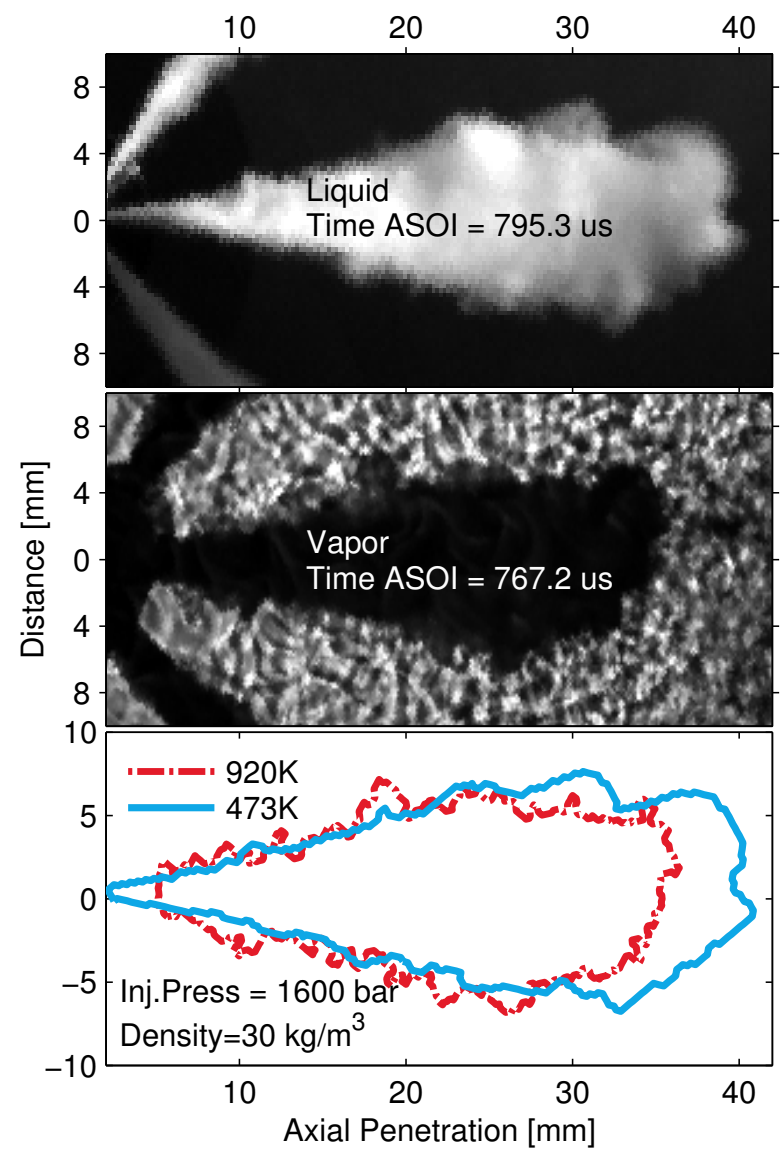

Figure 10: Comparisons between the contours obtained at vaporizing and non-vaporizing conditions.

\subsubsection{Nozzle D228}

In the same way as in the case of the nozzle with the smallest diameter (D194), the temperature comparison for the D228 nozzle is presented in Fig 11. Unfortunately, in this case, non-vaporizing data at $473 \mathrm{~K}$ is not available. The same trends than in the D194 nozzle are observed here, the temperature at vaporizing conditions does not play an important role in the vapor penetration, while it has a big contribution in the liquid phase penetration and stabilized liquid length. 
Final author version, cite as:

R. Payri, J. Gimeno, G. Bracho, D. Vaquerizo, Study of liquid and vapor phase behavior on Diesel sprays for heavy duty engine nozzles. Applied Thermal Engineering 107 (2016) 365-378. doi:10.1016/j.applthermaleng.2016.06.159

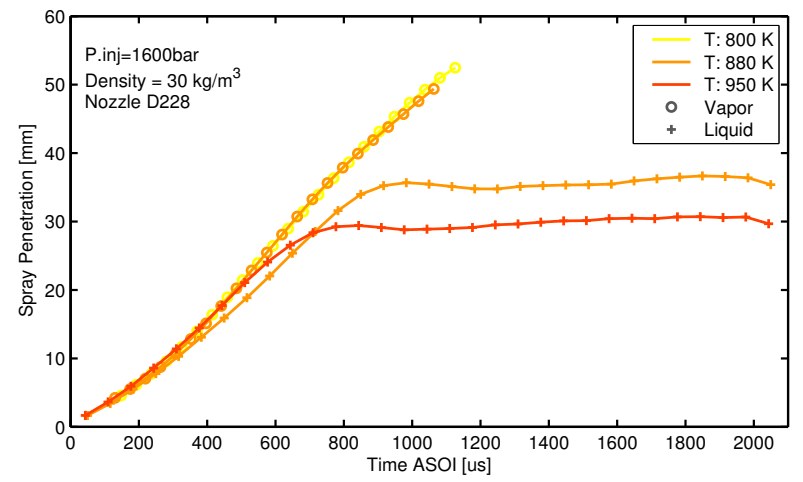

Figure 11: Comparison of the effect of gas temperature on the liquid and vapor spray penetrations in D228 Nozzle.

Fig 12 shows that for the D228 nozzle, the ambient gas temperature has an insignificant effect on the vapor spray spreading angle for the range of temperature considered $(880 \mathrm{~K}$ and $950 \mathrm{~K}$ ). For the vapor spray, once the fuel is in gaseous phase, the temperature alone does not influence air entrainment as it is mainly governed by the ambient density.

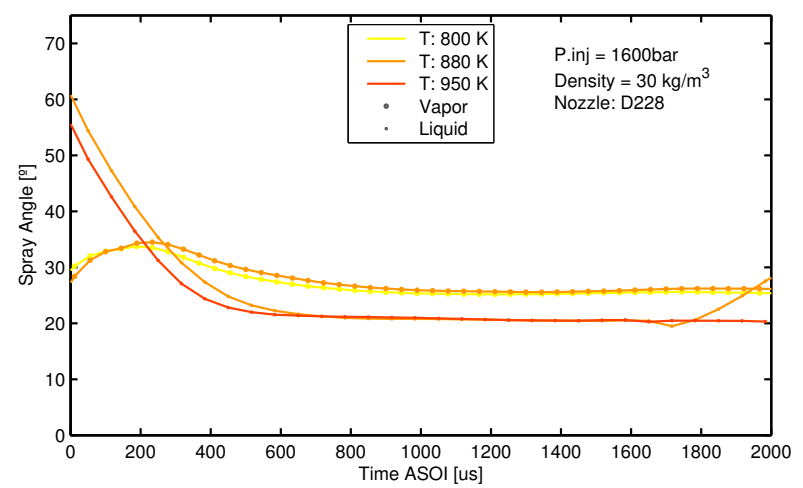

Figure 12: Spray angle at different temperatures for the D228 nozzle.

Fig 13 further details the behavior observed in Fig 12. In the tip region of the spray, the contour of the spray at lower temperature is larger than the one at the higher temperature, indicating less evaporation. However, it can be seen how the angle calculation algorithm would yield a very similar angle for the two contours, which might suggest that the evaporation rate in the transversal direction is similar for both temperatures. This phenomenon is an example of the limitations of the cone angle as a measure of the spray rate of evaporation, which can yield results that do not completely explain the phenomena taking place. 
Final author version, cite as:

R. Payri, J. Gimeno, G. Bracho, D. Vaquerizo, Study of liquid and vapor phase behavior on Diesel sprays for heavy duty engine nozzles. Applied Thermal Engineering 107 (2016) 365-378. doi:10.1016/j.applthermaleng.2016.06.159

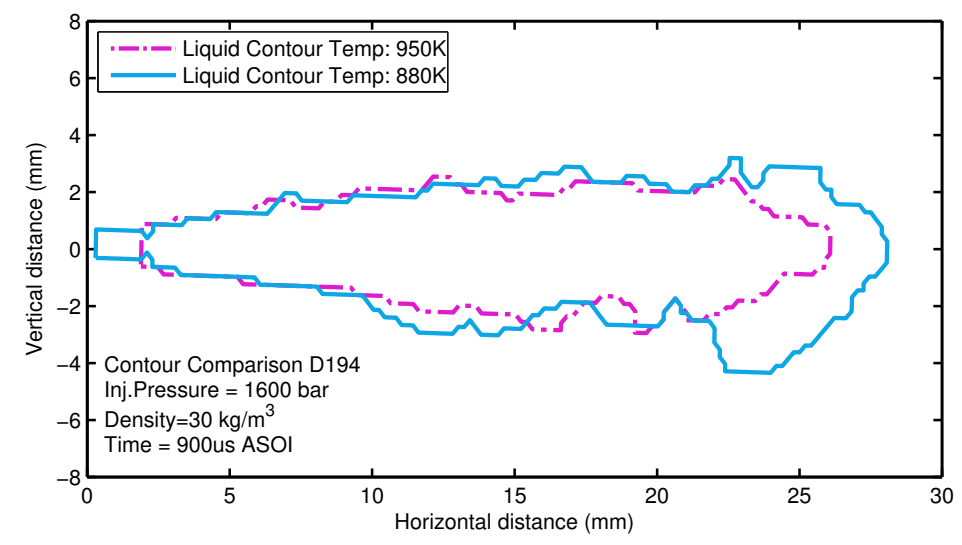

Figure 13: Contour comparison for the D194 at two different temperatures.

\subsection{Effect of nozzle diameter on spray morphology: liquid phase}

The test plan allows making several comparisons between the different nozzles tested to assess the effect of the diameter in the morphology of the spray.

Fig 14 shows a comparison of the liquid phase penetration in evaporative conditions for the D194 and D228 nozzles, at two injection pressure levels (100 and $210 \mathrm{MPa}$ ). The left side depicts the penetration curves for low gas density condition $20 \mathrm{~kg} / \mathrm{m}^{3}$, while the right figure shows results at high chamber density value of $40 \mathrm{~kg} / \mathrm{m}^{3}$. Both figures show how the nozzle diameter has negligible influence on the transient evolution of the spray (at the beginning of the injection event), nevertheless once the stabilized Liquid Length condition is reached, the diameter has an evident effect, where the bigger the nozzle diameter the longer the Liquid Length. Also, the diameter influence is more evident at the lowest gas density condition; on the contrary, when the density is considerably high, the diameter effect becomes less important. All these observations are in agreement with other studies, ensuring that the results are reliable $[10,28,30]$. One interesting fact is the large value of Liquid Length found (about $35 \mathrm{~mm}$ depending on the chamber condition). When these values are compared with some ECN reference cases as the spray A and B (90 $\mu \mathrm{m}$ nozzle diameters), in which LL is around $11 \mathrm{~mm}$, the scaling of the LL with the nozzle diameter can be easily appreciated. The ECN cases were chosen since those are a current guideline in the engine research field [31]. The large values of LL obtained in the present study for these big nozzles might be taken into account during the combustion chamber design in order to avoid wall/piston impingement. Also, interaction between liquid phase, gaseous phase and flame could occur if the flame lift off value is shorter than the Liquid Length measured [32]. This corroboration will be done in future studies.

The effect of the nozzle diameter on the liquid phase spreading angle at different gas densities and rail pressure values is presented in Fig 15. The test conditions are the same of those depicted in the liquid-phase penetration plot (Fig 14). As expected, the higher the gas density, the wider the spreading angle for all the diameters. On the contrary, the rail pressure influence is insignificant on the spray angle values. Fig 15 shows that the bigger the hole diameter, the wider the spray spreading angle. The nozzle geometry influence 
Final author version, cite as:

R. Payri, J. Gimeno, G. Bracho, D. Vaquerizo, Study of liquid and vapor phase behavior on Diesel sprays for heavy duty engine nozzles. Applied Thermal Engineering 107 (2016) 365-378. doi:10.1016/j.applthermaleng.2016.06.159
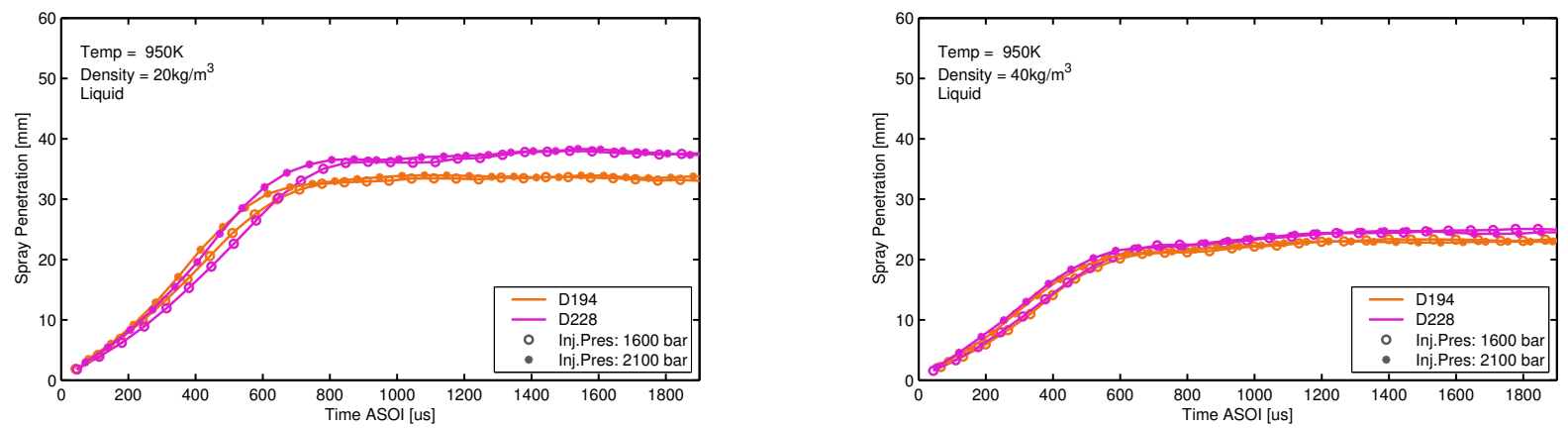

Figure 14: Effect of diameter in spray penetration at $20 \mathrm{~kg} / \mathrm{m}^{3}$ (left) and $40 \mathrm{~kg} / \mathrm{m}^{3}$ (right). Two different injection pressures are shown in each graph.

is more evident at the lower density value. The wider spray angle for the biggest nozzle D228 could be a combination of different facts: bigger nozzle diameter could increase the spreading angle, although it was not clearly demonstrated in the literature $[9,28,29]$. In contrast, lower area coefficient $\left(\mathrm{C}_{a}\right)$ will increase the spray angle value. Several studies have demonstrated that cavitation is linked with lower $\mathrm{C}_{a}$ and with an increase of the spray angle, even if the cavitation is not completely developed and fuel vapor is not formed continuously (but rather just some vapor bubbles are formed statistically) [33]. In the current study, both nozzles have the same hole length but different diameter, therefore, since D228 has lower L/D ratio might have more propensity for cavitation onset as demonstrated by [11], consequently a decrease of $\mathrm{C}_{a}$ promotes a wider spreading angle as is occurring.
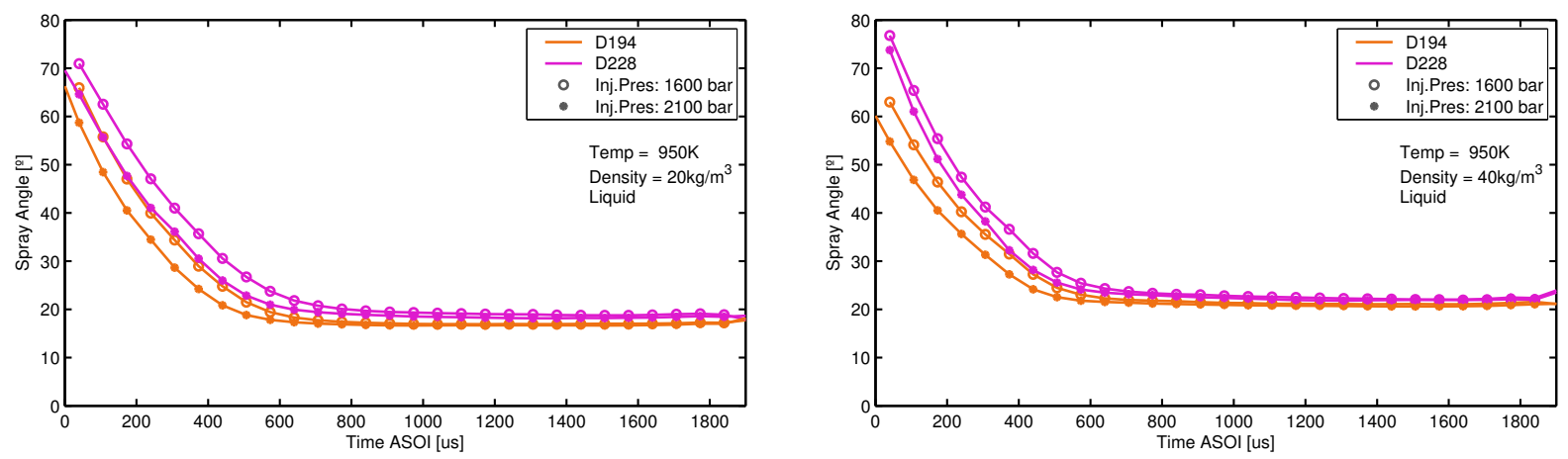

Figure 15: Angle comparison between the D194 and D228 nozzles at $20 \mathrm{~kg} / \mathrm{m}^{3}$ (left) and $40 \mathrm{~kg} / \mathrm{m}^{3}$ (right) densities at two different injection pressures.

As an extension of the presented results, Fig 16 also shows a comparison of the processed liquid-spray contour for both nozzles D194 and D228. It shows one repetition and an instant at stabilized conditions, which is representative for the majority of time-steps. It clearly shows how the bigger diameter nozzle produces longer and wider sprays; also, more instabilities are visible in the contour which could be related to the initiation of cavitation due to the lower $\mathrm{L} / \mathrm{D}$ ratio and $\mathrm{C}_{a}$ values. 
Final author version, cite as:

R. Payri, J. Gimeno, G. Bracho, D. Vaquerizo, Study of liquid and vapor phase behavior on Diesel sprays for heavy duty engine nozzles. Applied Thermal Engineering 107 (2016) 365-378. doi:10.1016/j.applthermaleng.2016.06.159

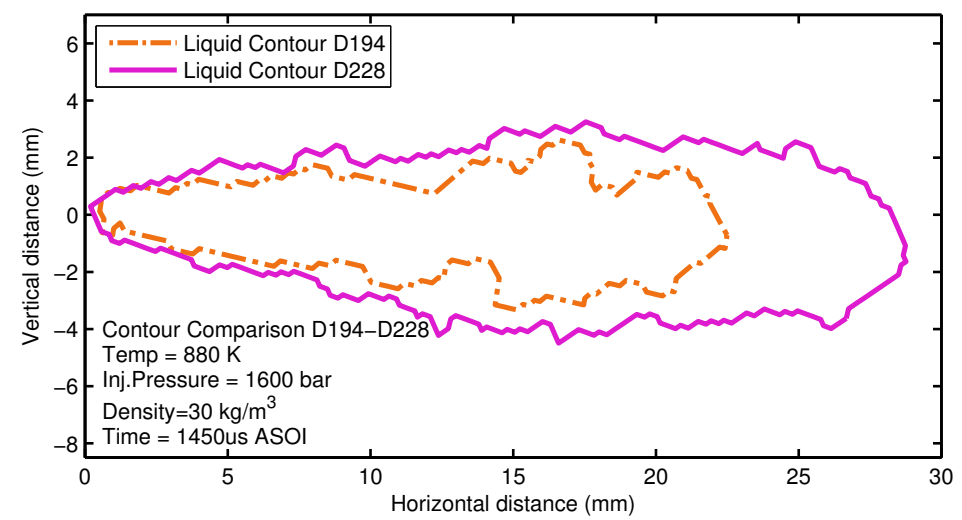

Figure 16: Liquid phase: Contour comparison between the D194 and D228

\subsection{Effect of nozzle diameter on spray morphology: vapor phase}

In the same way, the effect of the nozzle diameter on the vapor phase penetration is shown in figure 17, comparing nozzles D194 and D228, for two injection pressure levels and gas densities of $30 \mathrm{~kg} / \mathrm{m}^{3}$ and $40 \mathrm{~kg} / \mathrm{m}^{3}$.
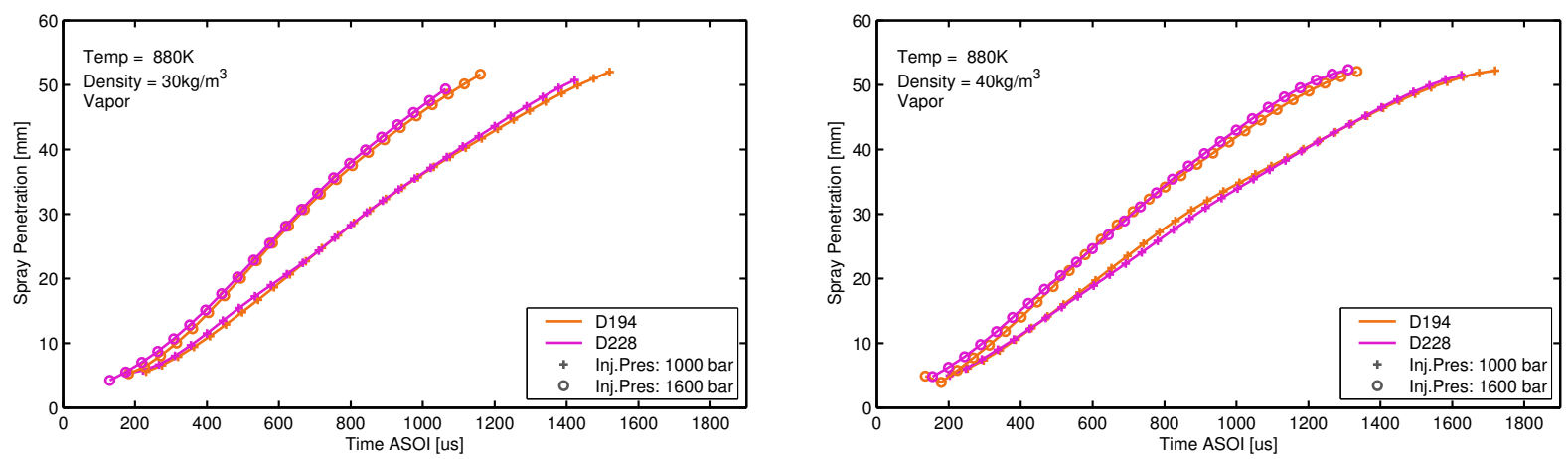

Figure 17: Vapor penetration comparison between the D194 and D228 nozzles at $30 \mathrm{~kg} / \mathrm{m}^{3}$ (left) and 40 $\mathrm{kg} / \mathrm{m}^{3}$ (right) densities at two different injection pressures.

In general, results show very little influence of the diameter, although literature suggests that outlet diameter increases spray penetration [28]. Specifically, nozzle diameter did not show a significant effect on the first instants of the vapor penetration, where the relationship with time is linear. Several researchers have demonstrated that the transitory zone of the spray penetration is independent on the nozzle diameter, where the dominant parameter is the flow velocity at the nozzle exit [34]. On the second region, in the so-called developed zone of the spray (where the relation between vapor penetration and time is approximately square root dependency) there is some influence of the nozzle diameter increasing the spray penetration. The instant where the spray penetration switches from the linear dependence to a square root time dependence is known as transition time $\left(\mathrm{t}_{r}\right)$, defined as the instant when the spray changes from being dominated by injected fluid to being dominated by entrained gas [9]. This transition time is proportional to nozzle 
Final author version, cite as:

R. Payri, J. Gimeno, G. Bracho, D. Vaquerizo, Study of liquid and vapor phase behavior on Diesel sprays for heavy duty engine nozzles. Applied Thermal Engineering 107 (2016) 365-378. doi:10.1016/j.applthermaleng.2016.06.159

diameter (as is shown in Section 4). The interesting fact is that in the present study the transition time is occurring very late, since the nozzle diameters are big (when compared to the majority of the researches available which are performed with smaller nozzle diameters of about $90 \mu \mathrm{m}$ ), therefore the linear region is big enough that it almost reaches the window limit used in the experiments.
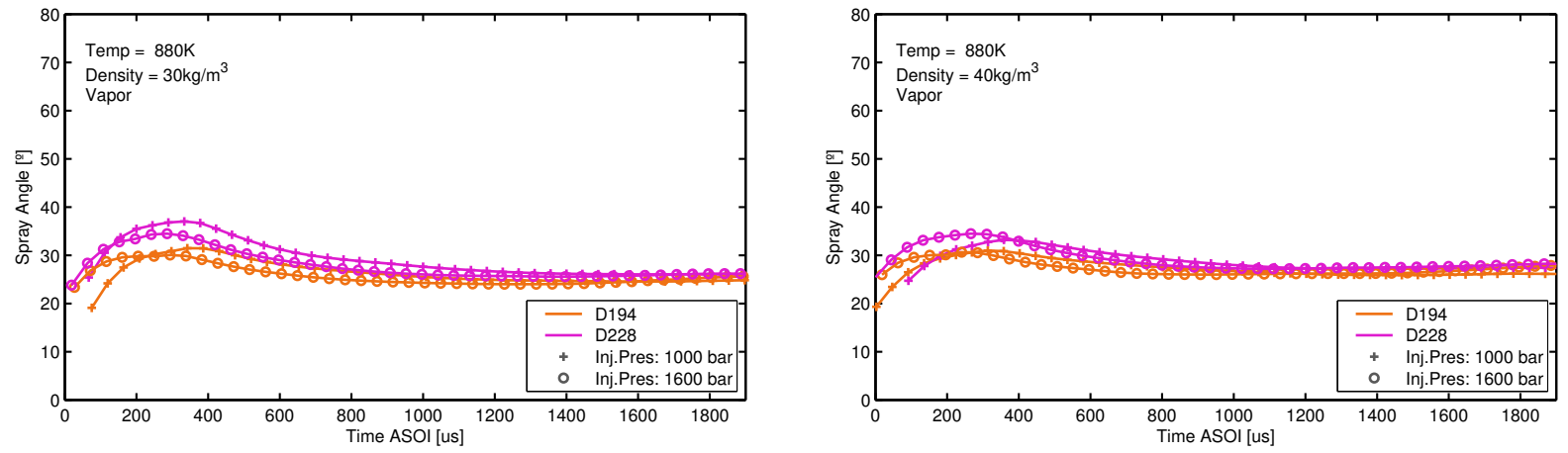

Figure 18: Vapor spray angle comparison between the D194 and D228 nozzles at $30 \mathrm{~kg} / \mathrm{m}^{3}$ (left) and 40 $\mathrm{kg} / \mathrm{m}^{3}$ (right) of gas densities at two different injection pressures.

Figure 18 shows the spray spreading angle for the same conditions of Figure 17. It can be seen that the nozzle diameter has minor influence on the spray spreading angle, especially if it is compared with the influence of other parameters as the gas density. However, if a conclusion must be made, the bigger nozzle diameter tends to produce slightly wider spray, which can be related to the more cavitating nature since it has a short $\mathrm{L} / \mathrm{D}$ ratio, as was mentioned before.

\section{Data Analysis}

\subsection{Introduction}

In this section, the data presented in section 3 is analyzed as a whole in order to extract empirical mathematical formulas that describe the behavior observed for the liquid and vapor penetration of the spray on the two nozzles. The motivation to extract the empirical formulas is on one hand, to provide a simple model for nozzles with similar sizes that can give a first estimation about the properties of injected sprays; and on the other hand, to analyze how well the results obtained with the experimental equipment and methodology used in this work agree with the results obtained by other authors such as Higgins et al. [35], Desantes et al. [36] or Payri et al. [25].

\subsection{Liquid phase analysis}

The study of the liquid phase of the spray is important for its relationship with critical parameters that greatly affect the combustion process as the Lift Off Length (LOL), the Ignition Delay (ID) or the possible impact of the spray with the walls of the combustion chamber and the piston bowl. The analysis of the liquid phase of the spray has been 
Final author version, cite as:

R. Payri, J. Gimeno, G. Bracho, D. Vaquerizo, Study of liquid and vapor phase behavior on Diesel sprays for heavy duty engine nozzles. Applied Thermal Engineering 107 (2016) 365-378. doi:10.1016/j.applthermaleng.2016.06.159

carried out focusing on the stabilized region of the spray or what is known as the Liquid Length (LL). Fig 19 shows the methodology employed to obtain the stabilized value of the liquid penetration. The time window used to calculate the average of the liquid penetration has been selected in order to properly capture the stabilized region for the different nozzles at the different operating points.

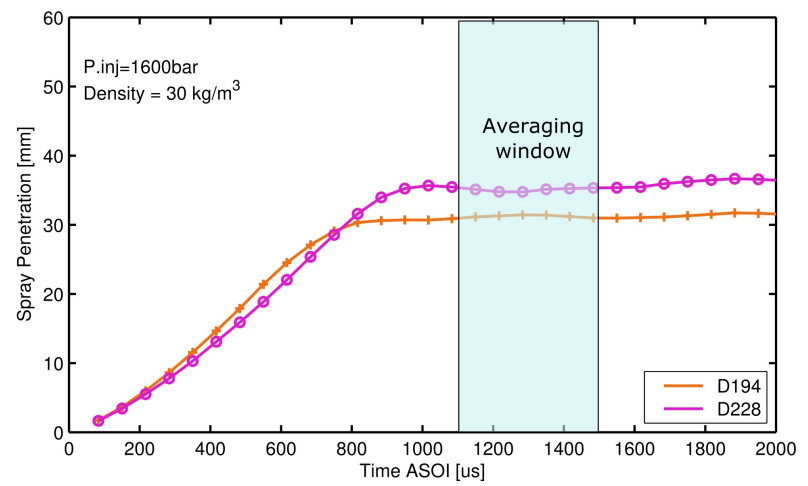

Figure 19: Liquid Penetration averaging methodology. Colored area represents the zone where the average has been calculated.

As was done by Payri et al. [25], or in the work of Desantes et al. [37]; the kind of expression selected to obtain a correlation that best describes the trends captured in the experimental campaigns has been an exponential type formula of the form presented in (5)

$$
L L=K \cdot D_{o}^{a} \cdot \rho_{a}^{b} \cdot T_{\text {gas }}^{c} \cdot \Delta P^{d}
$$

Where $D_{o}$ is the outlet diameter of the nozzles, $\rho_{a}$ is the gas ambient density, $T_{\text {gas }}$ is the gas ambient temperature; and $\Delta P$ is the pressure drop between the injector and the ambient. The rest of the variables $(K, a, b, c, d)$ are constants left free to fit the model to the experimental data. All the operating conditions that did not allow the liquid penetration to reach the stabilized region inside the visualization window of the camera have not been taken into account for the fitting procedure, such as the cold spray data at $473 \mathrm{~K}$ and the lower density conditions at $20 \mathrm{~kg} / \mathrm{m}^{3}$. Table 6 shows the values of the constants obtained to fit the model, and equation (6) shows the final form of the Liquid Length correlation obtained.

Table 6: Values of the fitted exponents for the Liquid Length correlation

\begin{tabular}{rccccc}
\hline Constant & $K$ & $a$ & $b$ & $c$ & $d$ \\
\hline Value & 60256 & 1.08 & -0.51 & -1.7 & -0.015 \\
\hline & $L L=\frac{60256 D_{o}^{1.08}}{\rho_{a}^{0.51} T_{\text {gas }}^{1.7} \Delta P^{0.015}}$
\end{tabular}


Final author version, cite as:

R. Payri, J. Gimeno, G. Bracho, D. Vaquerizo, Study of liquid and vapor phase behavior on Diesel sprays for heavy duty engine nozzles. Applied Thermal Engineering 107 (2016) 365-378. doi:10.1016/j.applthermaleng.2016.06.159

Figs 20a and 20b show plots of the Liquid Length model obtained (dashed line) together with the experimental data (dot and cross symbols) versus the ambient gas density at $880 \mathrm{~K}$ and $950 \mathrm{~K}$ respectively, whereas Figs 21a and 21b represent the Liquid Length experimental data and model versus gas temperature at $30 \mathrm{~kg} / \mathrm{m}^{3}$ and $40 \mathrm{~kg} / \mathrm{m}^{3}$ respectively. It can be noted that even though there are some points that are further away of the lines, the model captures the trend of the experimental data quite well and is able to describe the difference in stabilized Liquid Length for the different diameters and for the change in the operating temperature and density values experimented accurately.

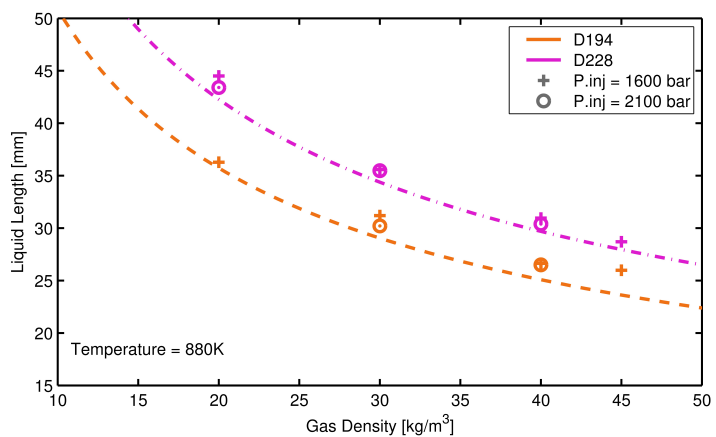

(a) Temperature $880 \mathrm{~K}$

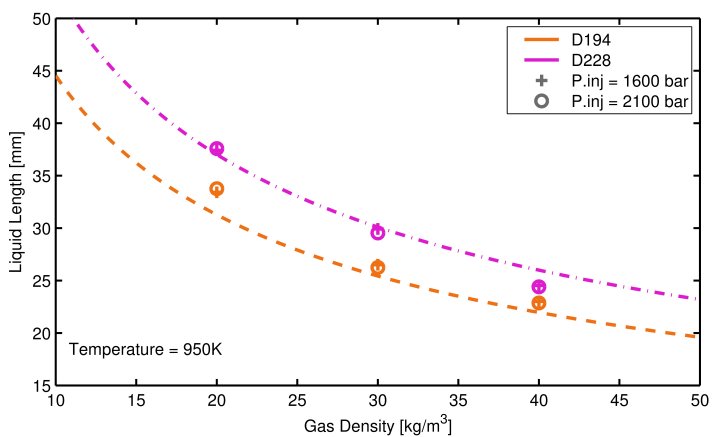

(b) Temperature $950 \mathrm{~K}$

Figure 20: Liquid Length experimental and model versus gas density at different temperatures. (a) 880 K, (b) $950 \mathrm{~K}$

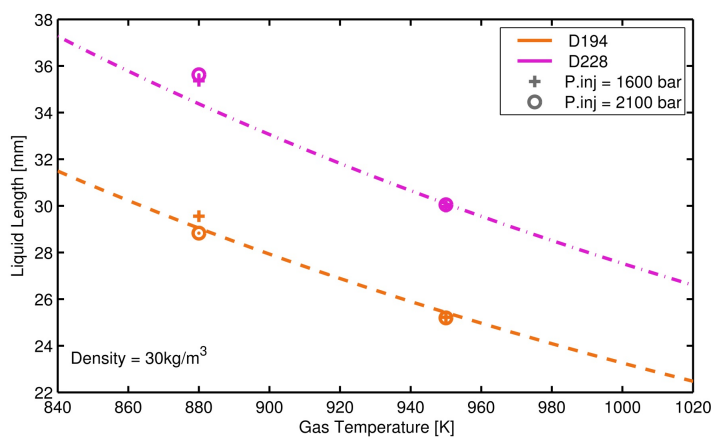

(a) Gas density $30 \mathrm{~kg} / \mathrm{m}^{3}$

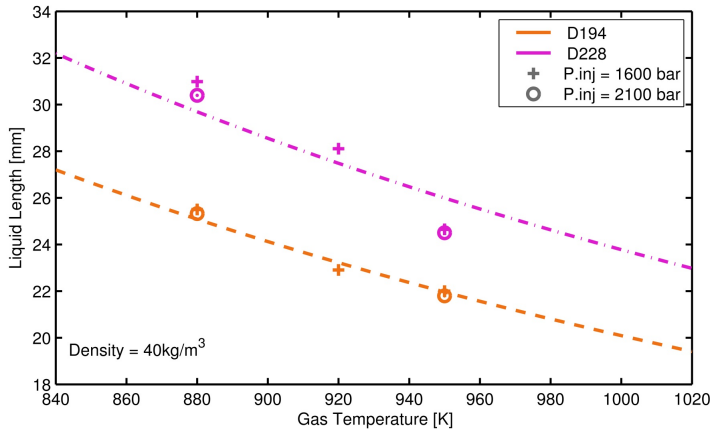

(b) Gas density $40 \mathrm{~kg} / \mathrm{m}^{3}$

Figure 21: Liquid Length experimental and model versus temperature at different gas densities. (a) 30 $\mathrm{kg} / \mathrm{m}^{3}$, (b) $40 \mathrm{~kg} /{ }^{3}$.

As mentioned in the introductory part of this section, other authors have taken a similar approach to describe the experimental data gathered by means of empirical equations that can serve to interpolate in between different conditions to get a first estimative result and to better understand how the different variables studied affect the results. Table 7 shows a comparison of the constants obtained in the current work and similar works performed in the past. Martínez-Martínez et al. [38] also performed similar mathematical correlations with several diameters, although they used a transparent engine for their 
Final author version, cite as:

R. Payri, J. Gimeno, G. Bracho, D. Vaquerizo, Study of liquid and vapor phase behavior on Diesel sprays for heavy duty engine nozzles. Applied Thermal Engineering 107 (2016) 365-378. doi:10.1016/j.applthermaleng.2016.06.159

research and different parameters in the equations. It can be seen in Table 7 that the constants accompanying the terms of density, temperature and diameter are similar in all cases which provides confidence in the experimental data gathered and in the final correlation proposed. It is worth underlying the high value of the exponent of the gas temperature, which gives this variable the most importance in the behavior of the Liquid Length. However, if the effect of the change in density is decoupled from the temperature, the absolute value of the temperature exponent would fall bellow the density exponent $[25]$.

Table 7: Comparisons of fitted exponents in the Liquid Length correlation in several works.

\begin{tabular}{rrrrrrr}
\hline & $K$ & $a$ & $b$ & $c$ & $d$ & $R^{2}[\%]$ \\
\hline Current work & 60256 & 1.08 & -0.51 & -1.7 & -0.015 & 95.1 \\
Desantes et al. [36] & Not shown & 1.09 & -0.523 & -1.143 & 0.069 & 96.2 \\
Payri et al. [25] & 51412 & 0.94 & -0.46 & -1.68 & 0.07 & 81.4 \\
\hline
\end{tabular}

\subsection{Vapor Phase Analysis}

This section analyses the experimental data gathered in Section 3 in a similar manner as above focusing on the images taken by means of the Schlieren methodology. The model employed in this section to explain the vapor phase of the sprays is similar to the one proposed by Payri et al. [27], Naber and Siebers [9], or the one developed and validated by Desantes et al. [26] and presented in section 2.8.2. The functions with the variable exponents presented here (in equations (7), (8) and (9)), differently from the model that Payri et al. [27] used, leave the exponent for the time free, in order to provide a better fit with the experimental data at the expense of the model being less physical. Also, the contribution from the area coefficient that is explicit in [27] has been introduced in the constants as the value was unavailable.

For $t<t_{r}$ :

$$
S(t)=K_{1} \cdot C_{v} \cdot \Delta P^{a_{1}} \cdot t^{b_{1}}
$$

For $t>t_{r}$ :

$$
S(t)=K_{2} \cdot \rho_{a}^{c_{2}} \cdot \Delta P^{a_{2}} \cdot \tan (\theta / 2)^{0.5} \cdot D_{0}^{0.5} \cdot t^{b_{2}}
$$

Where

$$
t_{r}=K_{r} \cdot D_{0} \cdot \rho_{a}^{c_{r}} \cdot \Delta P^{a_{r}}
$$

Table 8 shows the values obtained for the different exponents in the vapor penetration correlation.

In order to demonstrate the correlation for the two different nozzles and the two regions Figs $22 \mathrm{a}$ and $22 \mathrm{~b}$ are presented. The two figures show how the vapor penetration first behaves following the first correlation to then change to follow the second, the examples show good agreement between the correlations and the experimental data for the D194 and D228 nozzles and for the highest values of density tested. 
Final author version, cite as:

R. Payri, J. Gimeno, G. Bracho, D. Vaquerizo, Study of liquid and vapor phase behavior on Diesel sprays for heavy duty engine nozzles. Applied Thermal Engineering 107 (2016) 365-378. doi:10.1016/j.applthermaleng.2016.06.159

Table 8: Fitted exponents for the vapor penetration correlation.

\begin{tabular}{rrrrrr}
\hline Piece & $\mathrm{K}$ & $\mathrm{a}$ & $\mathrm{b}$ & $\mathrm{c}$ & $R^{2}[\%]$ \\
\hline$t<t_{r}\left(X_{1}\right)$ & 1,53 & 0,48 & 1,14 & & 98.6 \\
$t>t_{r}\left(X_{2}\right)$ & 0,31 & 0,28 & 0,68 & $-0,15$ & 85.5 \\
$t_{r}\left(X_{r}\right)$ & 0,26 & $-0,33$ & & $-0,47$ & 88.6 \\
\hline
\end{tabular}

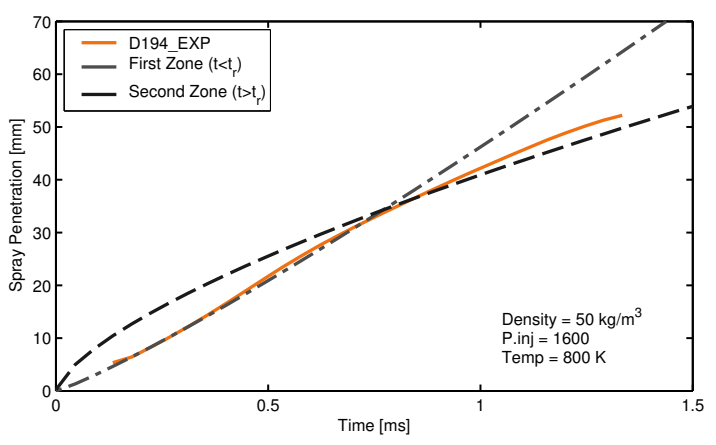

(a) D194

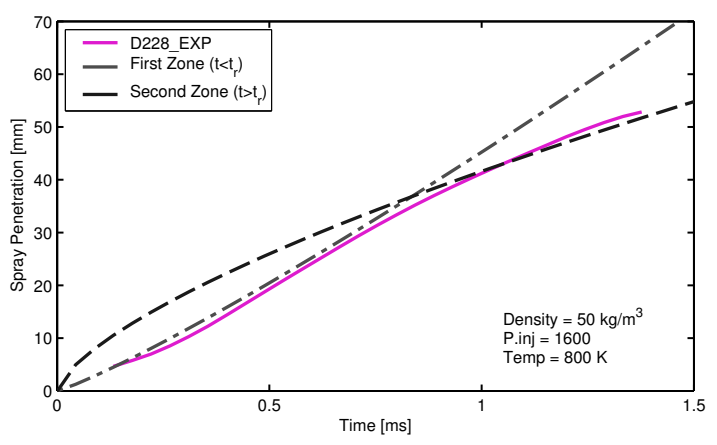

(b) D228

Figure 22: Piece-wise correlation versus experimental data for the two nozzles experimented.

Summarizing, from the results and the theoretical analysis presented, the following comments can be drawn: bigger nozzle diameter will lead longer transition time; therefore, the linear dependency of the spray penetration with time is larger. Then, in order to have more accurate fittings of the spray in the developed region, the experimental data for these big nozzles should be done in chambers with bigger optical accesses. In addition, although the spray penetration correlation was obtained from evaporative data, it could be employed as a rough estimation for non-evaporative cases especially for high gas density values, keeping in mind that sprays in evaporative conditions can penetrate slower than sprays in conditions with the same ambient density but with no evaporation taking place (as shown in section 3).

\section{Conclusions}

Two nozzles with diameters of 194 and $228 \mu \mathrm{m}$ have been tested in a High Pressure and High Temperature test rig while using Mie scattering and Schlieren optical techniques with the purpose of evaluating the effect of density, nozzle diameter and gas temperature on the spray penetration and spray angle. The main conclusions gathered throughout the work can be summarized as follows:

1. Gas temperature has very little effect on vapor penetration when maintaining density. The effect was only noticeable when comparing the results from vaporizing and non-vaporizing conditions (at $473 \mathrm{~K}$ ), where a difference in the rate of vapor penetration, angle and spray morphology could be noted. The vapor penetration insensitivity to the gas temperature has been confirmed for the two different nozzles, 
proving that the effect is not dependent on the diameter for the ranges studied in this work.

2. Gas temperature has a big effect on liquid penetration and Liquid Length. The global effect quantified by the modeling equation in the Analysis section was almost an inverse cuadratic relation with the Liquid Length, which proves the importance of closely controlling the parameter whether in engine operation or visualization campaigns. The effect of the gas temperature was not as clear for $880 \mathrm{~K}$ and $920 \mathrm{~K}$ for the D228 nozzle and the reason was attributed to the more cavitating trend operation of the nozzle.

3. Nozzle diameter did not show an effect on the first instants of the vapor penetration, where the relation with time is linear. On the second part of the penetration curve, where the relation between vapor penetration and time is approximately quadratic, a proportional effect of nozzle diameter on vapor penetration has been shown.

4. The analysis section where the correlation of the liquid and vapor penetration curves have been performed helped quantifying the relation between the different variables investigated in the work and the development on the injected spray. The correlations can be used to provide a first estimate of Liquid Length and vapor penetration curves for nozzles of big diameters and a wide variety of injection pressure, density and gas temperature conditions relevant to engine operation.

\section{Funding}

This work was sponsored by "Ministerio de Economía y Competitividad" in the frame of the project "Estudio de la interacción chorro-pared en condiciones realistas de motor (SPRAY WALL)" reference TRA2015-67679-c2-1-R.

Daniel Vaquerizo is partially supported through contract FPI-S2-2015-1069 of Programa de Apoyo para la Investigación y Desarrollo (PAID) of Universitat Politècnica de València

\section{Acknowledgments}

The authors would like to thank José Enrique del Rey for his collaboration in the experimental measurements. 


\section{References}

[1] K. Nikzadfar, A. H. Shamekhi, More than one decade with development of commonrail diesel engine management systems: a literature review on modelling, control, estimation and calibration, Proceedings of the Institution of Mechanical Engineers, Part D: Journal of Automobile Engineering 229 (2014) 1110-1142.

[2] R. Payri, J. Gimeno, P. Martí-Aldaraví, D. Vaquerizo, Internal flow characterization on an ECN GDi injector, Atomization and Sprays 26 (9) (2016) 889-919.

[3] T. V. Johnson, Diesel emissions in review, SAE International Journal of Engines 4 (2011-01-0304) (2011) 143-157.

[4] I. A. Khalek, M. G. Blanks, P. M. Merritt, B. Zielinska, Regulated and unregulated emissions from modern 2010 emissions-compliant heavy-duty on-highway diesel engines, Journal of the Air \& Waste Management Association 65 (8) (2015) 987-1001.

[5] C. Kendlbacher, C. Meisl, R. S. M. Bernhaupt, D. Blatterer, T. Lengenfelder, Das 2200 bar Modulare Common Rail Einspritzsystem für Diesel und Schweröl Großmotoren, in: DER ARBEITSPROZESS DES VERBRENNUNGSMOTORS", Institut für Verbrennungskraftmaschinen und Thermodynamik, Technische Universität Graz, 548-565, 2013.

[6] A. Kastengren, F. T. Zak, C. F. Powell, J. Manin, L. M. Pickett, R. Payri, T. Bazyn, Engine Combustion Network (ECN): measurements of nozzle geometry and hydraulic behavior, Atomization and Sprays 22 (12) (2012) 1011-1052.

[7] R. Payri, J. M. Garcia-Oliver, T. Xuan, M. Bardi, A study on diesel spray tip penetration and radial expansion under reacting conditions, Applied Thermal Engineering 90 (2015) 619-629.

[8] R. Payri, F. J. Salvador, J. Manin, A. Viera, Diesel ignition delay and lift-off length through different methodologies using a multi-hole injector, Applied Energy 162 (2016) 541-550.

[9] J. D. Naber, D. Siebers, Effects of gas density and vaporization on penetration and dispersion of Diesel sprays, SAE Technical Paper 960034105 (412) (1996) 82-111.

[10] D. Siebers, Scaling liquid-phase fuel penetration in Diesel sprays based on mixinglimited vaporization, SAE Technical Paper 1999-01-0528 .

[11] O. Venegas, Estudio del fenómeno de la cavitación en la inyección diesel mediante la visualización del flujo interno en orificios transparentes., Ph.D. thesis, Universidad Poltécnica de València-Departamento de Máquinas y Motores Térmicos, 2014. 
[12] R. Payri, J. Gimeno, J. P. Viera, A. H. Plazas, Needle lift profile influence on the vapor phase penetration for a prototype diesel direct acting piezoelectric injector, Fuel 113 (2013) 257-265.

[13] R. S. Baert, P. J. Frijters, B. Somers, C. C. Luijten, W. de Boer, Design and operation of a high pressure, high temperature cell for HD diesel spray diagnostics: guidelines and results, SAE Technical Paper 2009-01-0649 4970.

[14] S. E. Parrish, R. Zink, Development and Application of Imaging System to Evaluate Liquid and Vapor Envelopes of Multi-Hole Gasoline Fuel Injector Sprays under Engine-like Conditions, Atomization and Sprays 22 (8) (2012) 647-661.

[15] B. T. Fisher, C. J. Mueller, Liquid penetration length of heptamethylnonane and trimethylpentane under unsteady in-cylinder conditions, Fuel 89 (10) (2010) 26732696.

[16] C. J. Mueller, G. C. Martin, T. E. Briggs, K. P. Duffy, An experimental investigation of in-cylinder processes under dual-injection conditions in a DI diesel engine, SAE Technical Paper 2004-01-1843 .

[17] M. Bardi, R. Payri, L. M. Malbec, G. Bruneaux, L. M. Pickett, J. Manin, T. Bazyn, C. Genzale, Engine Combustion Network: comparison of spray development, vaporization, and combustion in different combustion vessels, Atomization and Sprays 22 (10) (2012) 807-842.

[18] L. M. Pickett, C. L. Genzale, J. Manin, L.-M. Malbec, L. Hermant, Measurement Uncertainty of Liquid Penetration in Evaporating Diesel Sprays, in: ILASS Americas, 23rd Annual Conference on Liquid Atomization and Spray Systems, May, ILASSAmericas, Ventura, CA (USA), 2011.

[19] L. M. Pickett, J. Manin, C. L. Genzale, D. L. Siebers, M. P. B. Musculus, C. A. Idicheria, Relationship Between Diesel Fuel Spray Vapor Penetration/Dispersion and Local Fuel Mixture Fraction, SAE International Journal of Engines 4 (1) (2011) 764799 .

[20] G. S. Settles, Schileren and Shadowgraphy Techniques. Visualizing Phenomena in Transparent Media, Springer, 2006.

[21] R. Payri, F. Salvador, A. Garcia, A. Gil, Combination of visualization techniques for the analysis of evaporating diesel sprays, Energy \& Fuels 26 (9) (2012) 5481-5490.

[22] V. Macian, R. Payri, A. Garcia, M. Bardi, Experimental Evaluation of the Best Approach for Diesel Spray Images Segmentation, Experimental Techniques 36 (6) (2012) 26-34.

[23] D. Siebers, Liquid-phase fuel penetration in Diesel sprays, SAE Technical Paper 980809 . 
[24] R. Payri, J. Gimeno, M. Bardi, A. Plazas, Effect of injection rate shaping over diesel spray development in non reacting evaporative conditions, in: ASME 2012 Internal Combustion Engine Division Spring Technical Conference, American Society of Mechanical Engineers, 347-356, 2012.

[25] R. Payri, F. Salvador, J. Gimeno, L. Zapata, Diesel nozzle geometry influence on spray liquid-phase fuel penetration in evaporative conditions, Fuel 87 (7) (2008) 1165-1176.

[26] J. M. Desantes, R. Payri, F. Salvador, A. Gil, Development and validation of a theoretical model for Diesel spray penetration, Fuel 85 (7-8) (2006) 910-917.

[27] R. Payri, F. Salvador, J. Gimeno, R. Novella, Flow regime effects on non-cavitating injection nozzles over spray behavior, International Journal of Heat and Fluid Flow 32 (1) (2010) 273-284.

[28] F. Payri, R. Payri, M. Bardi, M. Carreres, Engine combustion network: Influence of the gas properties on the spray penetration and spreading angle, Experimental Thermal and Fluid Science 53 (2014) 236-243.

[29] M. Bardi, Partial needle lift and injection rate shape effect on the formation and combustion of the diesel spray., Ph.D. thesis, Universidad Politecnica de Valencia., 2014.

[30] J. V. Pastor, R. Payri, J. M. Garcia-Oliver, F. J. Briceno, Analysis of transient liquid and vapor phase penetration for diesel sprays under variable injection conditions, Atomization and Sprays 21 (6) (2011) 503-520.

[31] R. Payri, J. M. García-Oliver, M. Bardi, J. Manin, Fuel temperature influence on diesel sprays in inert and reacting conditions, Applied Thermal Engineering 35 (2012) $185-195$.

[32] D. L. Siebers, B. Higgins, Flame Lift-Off on Direct-Injection Diesel Sprays Under Quiescent Conditions, SAE Technical Paper 2001-01-0530 (724).

[33] R. Payri, J. Gimeno, M. Bardi, A. H. Plazas, Study liquid length penetration results obtained with a direct acting piezo electric injector, Applied Energy 106 (2013) 152162.

[34] H. Hiroyasu, M. Arai, Structures of fuel sprays in Diesel engines, SAE Technical Paper 900475 .

[35] B. S. Higgins, C. J. Mueller, D. L. Siebers, Measurements of fuel effects on liquidphase penetration in DI sprays, SAE Technical Paper 1999-01-0519 108 (724) (1999) 630-643. 
[36] J. M. Desantes, R. Payri, J. M. Pastor, J. Gimeno, Experimental characterization of internal nozzle flow and diesel spray behavior. Part I: Non evaporative conditions, Atomization And Sprays 15 (5) (2005) 489-516.

[37] J. M. Desantes, J. Pastor, R. Payri, J. Pastor, Experimental characterization of internal nozzle flow and Diesel spray behavior. Part II: Evaporative conditions, Atomization And Sprays 15 (5) (2005) 517-543.

[38] S. Martínez-Martínez, F. Sánchez-Cruz, J. Riesco-Ávila, A. Gallegos-Muñoz, S. Aceves, Liquid penetration length in direct diesel fuel injection, Applied Thermal Engineering 28 (14-15) (2008) 1756-1762. 